\title{
Comparison of terrestrial and Martian TEC at dawn and dusk during solstices
}

\author{
Angeline G. Burrell ${ }^{* *} \mathbb{D}$, Beatriz Sánchez-Cano², Olivier Witasse ${ }^{3}$, Mark Lester ${ }^{2}$ and Marco Cartacci ${ }^{4}$
}

\begin{abstract}
This paper used the similarities between the ionospheres on Mars and Earth, the most similar of the terrestrial planets, to examine the relative importance of photochemical and transport processes at dawn and dusk. The amount of plasma present in the ionosphere, as measured by the total electron content (TEC), was examined at different locations for both solstice seasons over a solar cycle. Using the rate of change of TEC as a function of solar zenith angle made it possible to compare the plasma production via photoionisation and loss via recombination in the main layer of each planetary ionosphere despite the extreme differences in the total quantity of plasma. This study finds that, at least to first order, the dawn and dusk TEC slopes at Mars are symmetric. This symmetry is interpreted as an indicator of photochemical equilibrium. Deviations from photochemical equilibrium in different geographic and aerographic regions were used to explore the underlying processes responsible for plasma transport. Seasonal and solar cycle variations were also examined at dusk. These variations found that differing interactions with solar forcing mechanisms resulted in a Martian ionosphere with regions that showed evidence of significant transport processes at solar maximum, while at Earth transport processes were most important at solar minimum. In general, the photochemical processes in both ionospheres behave similarly when no magnetic field is considered. The presence or absence of a magnetic field shape the production via photoionisation and loss via recombination processes in both ionospheres, especially when considering plasma transport. This study has notable implications for comparative aeronomy, as a good understanding of how the ionosphere of magnetised and un-magnetised bodies compares is important for characterising planetary environments and atmospheric evolution over long time scales.
\end{abstract}

Keywords: Earth, Mars, lonosphere, Comparative aeronomy, Total electron content

\section{Introduction}

Ionospheres are the charged regions that exist within the upper atmospheres of planets, moons, and minor bodies of the Solar and other Stellar Systems. Each Solar System body that has sufficient neutral atmosphere, especially within the inner part of the Solar System, has an ionosphere that is mainly formed by the solar ionising radiation at extreme-ultraviolet (EUV) and X-ray wavelengths (e.g., Witasse et al. 2008; Mendillo et al. 2016). The Earth and Mars are often considered to be the most similar of the terrestrial planets, with similar axial tilts (similar

\footnotetext{
*Correspondence: angeline.burrell@nrl.navy.mil

1 Space Science Division, U.S. Naval Research Laboratory, Washington D.C., USA

Full list of author information is available at the end of the article
}

seasons, although longer at Mars), similar length of the day, and both having water at (or near) its surface, albeit on different scales and with different distributions (Orosei et al. 2018). These similarities invite comparisons, though care must be taken to account for the major differences, which include a strong, intrinsic magnetic field at Earth, a longer year at Mars, and the greater eccentricity of the Martian orbit.

The ionospheres of Earth and Mars also share many similarities, such as a purely photochemical ionosphere formed mainly by $\mathrm{O}^{+}$and $\mathrm{O}_{2}^{+}$, and similar electron densities $\left(\sim 10^{11} \mathrm{~m}^{-3}\right)$ and altitudes $(\sim 135 \mathrm{~km})$ of some of their layers (for example, the main ionospheric layer at Mars and the secondary layer at Earth that is called the E-layer) (e.g., Hanson et al. 1977; Mendillo et al. 2011; Benna et al. 2015). However, one of the main differences 
is the presence of a denser and higher ionospheric layer at Earth that it is not found at Mars. This terrestrial layer is the so-called F-region, found at about $300 \mathrm{~km}$. The F-region is controlled by a mix of photochemistry and dynamic processes, and is where the maximum electron density of terrestrial ionosphere occurs (e.g., Mendillo et al. 2016).

At night, the absence of solar photoionisation highlights the differences between the compositions of the Martian and terrestrial ionospheres. Photochemical recombination alters the ionospheric composition, leading to a Martian ionosphere that is still $\mathrm{O}_{2}^{+}$above $130 \mathrm{~km}$, but changes to having $\mathrm{NO}^{+}$as the most abundant ion below this altitude (e.g.,Girazian et al. 2017). At Earth, $\mathrm{O}^{+}$remains the most abundant ion in the F-region, with $\mathrm{O}_{2}^{+}, \mathrm{N}_{2}^{+}$, and $\mathrm{NO}^{+}$playing important roles in the E-region (Schunk and Nagy 2009). The Martian nightside ionosphere near the terminator is maintained thanks to dayto-night plasma transport (e.g., Chen et al. 1978; Cui et al. 2015) together with impact ionisation by precipitating electrons (e.g., Cao et al. 2019), where densities of the major ions decrease with the solar zenith angle (SZA) across the terminator (e.g., Girazian et al. 2017; Withers et al. 2012). Far from the terminator, electron precipitation is the dominant source of ionisation, which is more important over regions of strong crustal magnetic fields (as will be described in the Section "Planetary environments") (e.g., Nĕmec et al. 2010; Lillis et al. 2018), and during solar storms (e.g., Sánchez-Cano et al. 2019). Transport also plays a large role maintaining the nighttime ionosphere at Earth, with current systems leading to $\mathbf{E} \times \mathbf{B}$ drifts and neutral winds driving field-aligned motions that may both lift and move plasma to less dense regions where ion loss through photochemical recombination occurs more slowly (e.g., Heelis 2004). These processes work alongside downward diffusion to maintain the nighttime F-region ionosphere at Earth.

The large exploration effort of Mars for the last 50 years, makes Mars the first body beyond Earth where comparative aeronomy studies start to be possible. Past comparisons between Earth and Mars environments have taken advantage of this increased body of ionospheric data. Mendillo et al. (2003) and Rishbeth and Mendillo (2004) found that day-to-day changes in solar irradiance have a similar impact on the photochemical ionospheric layers at Earth and Mars at different pressure levels. Moreover, this demonstrated that the major contributions to daily variability were correlated with solar irradiance, which had a larger effect at Mars than at Earth. Mendillo et al. (2003) also found that the influence of the lower atmospheric coupling is an important factor for the daily ionospheric variability at both planets. In particular, Bougher et al. (2004) found that the peak altitude of the main ionospheric layer at Mars has a strong annual oscillation when the same longitude is considered, and it is caused by nonmigratory thermal tides. This is a well-known phenomenon that also occurs at Earth (e.g., Hagan and Forbes 2002; Immel et al. 2006). However, some aspects of this coupling have some singularities at Mars. For example, there is a seasonal and dust-driven inflation and contraction of the entire Martian atmosphere (Bougher et al. 2006). The large amounts of suspended dust in the lower atmosphere, commonly produced during dust storms, lead to an increase in the altitude of the peak electron density that can be as large as $\sim 30 \mathrm{~km}$ (Wang and Nielsen 2003). Additionally, lower atmospheric cycles such as the $\mathrm{CO}_{2}$ cycle appear to produce a seasonal increase in the total amount of ionisation in the Martian ionosphere (Sánchez-Cano et al. 2018).

Despite the large number of similarities between both ionospheres, the presence of an intense global magnetic field at Earth and the lack of one at Mars produces a completely different picture of the interaction of each planet with the solar wind. As will be described in the Section "Planetary environments", the terrestrial magnetic field extends far beyond the terrestrial surface and atmosphere to form a magnetosphere that interacts with the solar wind. The Martian ionosphere, on the other hand, is the primary obstacle encountered by the solar wind, causing the Interplanetary Magnetic Field (IMF) carried by the solar wind to drape around Mars. Thus, although the general ionosphere formation mechanism is the same at both planets, they are modulated differently by each magnetic environment. The objective of this paper is to assess how different the ionosphere formation is at Earth and Mars and explore their underlying processes, especially in the morning and evening sectors where the production via photoionisation and loss via recombination mechanisms are more significant. This kind of comparison is important because it provides insight on how similar ionospheric features behave under different magnetic circumstances, as well as insight on the evolution of the Martian ionosphere from the time when it had a global magnetic field. To that end, a similar analysis based on similar data sets at both planets has been performed, focusing on the dawn and dusk sectors at the winter and summer solstices.

\section{Planetary environments}

Before performing a comparison between the terrestrial and Martian ionospheres, it is important to understand the degree of similarity between these two planets. This section provides an overview of the similarities and differences in the planetary size, heliocentric distance, planetary tilt, magnetic fields, solar wind interactions, solar irradiance, and neutral atmosphere of both planets. 
These discussions focus on the impact of these characteristics on the planetary ionosphere, to inform the results and discussion presented in the Section "Results and discussion".

\section{Planetary size and orientation}

The planetary size and heliocentric distance are two of the major differences between the Earth and Mars. Earth has a mean radius of $6371.0 \mathrm{~km}$ and a mass of $6.0 \times 10^{24}$ $\mathrm{kg}$, yielding a surface gravity $\left(\mathrm{g}_{\oplus_{\mathrm{s}}}\right)$ of $-9.8 \mathrm{~m} \mathrm{~s}^{-2}$. At 350 $\mathrm{km}$, the nominal altitude of the ion density peak, this translates to $\mathrm{g}_{\oplus_{i}}=-8.8 \mathrm{~m} \mathrm{~s}^{-2}$. Meanwhile, Mars has a mean radius of $3389.5 \mathrm{~km}$ and a mass of $6.4 \times 10^{23} \mathrm{~kg}$, yielding a surface gravity $\left(g_{i}\right)$ of $-3.7 \mathrm{~m} \mathrm{~s}^{-2}$. At $135 \mathrm{~km}$, the nominal altitude of the ion density peak, this translates to $g_{\sigma_{s}^{\prime}}$. The differences in gravitational acceleration affect the atmospheric scale heights, as well as other processes that may have played a key role in Mars evolution, such as the exosphere extension and atmospheric escape rates (e.g., Halekas 2017).

Mars has a more eccentric orbit than Earth, with aphelion at $1.66 \mathrm{AU}$ and perihelion at 1.38 AU. In comparison, Earth has an aphelion of $1.02 \mathrm{AU}$ and a perihelion of $0.98 \mathrm{AU}$. This means that the distance between aphelion and perihelion at Mars is a third of Earth's distance to the Sun, which has strong consequences for the amount of solar radiation that reaches Mars each season, and therefore, for the ionosphere. The eccentricity in the terrestrial orbit contributes to annual variations in the neutral density and TEC of the order of $3.4 \%$ and $7 \%$, respectively (Azpilicueta et al. 2011). However, because the Martian eccentricity is seven times greater, the annual variations in neutral density and TEC are much larger. As a consequence, the strength of the annual variation of the ionospheric density due to the orbital eccentricity is very pronounced at Mars, with the Martian TEC having an annual sinusoidal variation that follows the EUV solar radiation flux as modulated by the Mars-Sun distance. Therefore, the orbital eccentricity plays a dominant role on the climatological behaviour of the Martian ionosphere (e.g., Bergeot et al. 2019). Moreover, the variations in the EUV solar radiation flux create changes in the atmospheric and plasma scale heights, electron and neutral temperatures, as well as in the balance pressure between the dynamic pressure of the solar wind and the thermal pressure of the ionosphere that affect the TEC (Sánchez-Cano et al. 2015a, 2016; Bergeot et al. 2019). Annual variations in the neutral atmosphere have also been identified (Zou et al. 2011; González-Galindo et al. 2013; Sánchez-Cano et al. 2018; Bergeot et al. 2019).

The axial tilt and length of day at both planets are very similar, leading to analogous diurnal variations in solar irradiance with season. At Earth, the axial tilt is $23.44^{\circ}$ and the length of day is $86,400 \mathrm{~s}$. At Mars, the axial tilt is $25.19^{\circ}$ and the length of day (known as a sol) is $88,775 \mathrm{~s}$.

\section{Magnetic field}

Charged particles are greatly influenced by the presence of a magnetic field. When the magnetic field is strong enough, it constrains transport in an ionosphere by 'freezing-in' the plasma to the magnetic field lines (e.g., Syrovatskii 1978). At Earth and Mars, major differences in the planetary magnetic fields affect both ionospheric structure and the interactions between the ionosphere and the solar wind.

The Earth has a global-scale internal magnetic field that extends far beyond the planetary atmosphere and interacts with the solar wind. To first order, this magnetic field is an off-center dipole that is compressed on the sunward and stretched on the anti-sunward side of the planet as the IMF embedded in the solar wind connects to the high-latitude terrestrial magnetic field lines and drags them away from the Sun before they reconnect tens of Earth radii away from the planet (Dungey 1961). Near the surface of the Earth, higher order deviations from the dipole field approximation become more important. Figure 1 shows the magnetic declination (top) and field strength (bottom) at $350 \mathrm{~km}$ above the surface of the Earth for 1 Jan 2006, as specified by the International Geomagnetic Reference Field (Macmillan and Finlay 2010). This altitude was chosen for Fig. 1, because it typically lies close to the altitude of the ion density peak.

The terrestrial ionosphere can be organized into regions based on the types of interactions with the geomagnetic field. At low altitudes (E-region) where the neutral density is large, the mass difference between ions and electrons allows neutral winds to drive currents that create electric fields. At higher altitudes (F-region), ions and electrons move together. This motion occurs preferentially along field lines, since the 'frozen-in' condition of the plasma requires an electric field large enough to move all of the plasma along a given field line to create field-perpendicular ion drifts.

At high latitudes, magnetic field lines are oriented vertically and extend far into the magnetosphere or are directly connected to the IMF. This leads to phenomena such as high-energy particle precipitation, aurora, and 'convective' motion (Kelley 2009). At low latitudes, the magnetic field lines are oriented horizontally, allowing rapid transport between hemispheres. Combined with the presence of a diurnally varying dawn-to-dusk electric field, this leads to the 'fountain effect' that creates the Equatorial Ionisation Anomaly (EIA), which is made up of large enhancements of plasma on either side of the magnetic equator (Hanson and Moffett 1966). At 


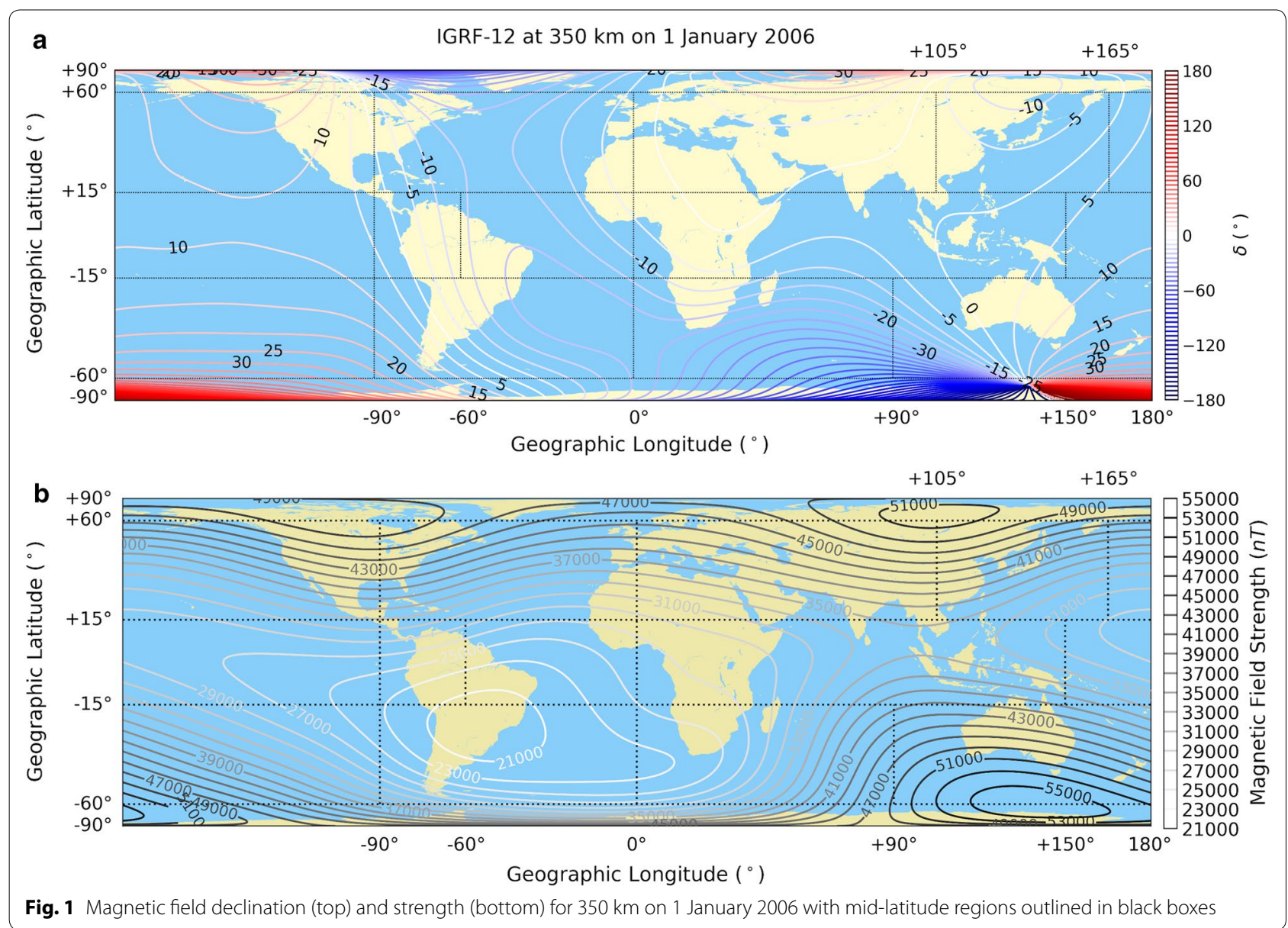

mid-latitudes, magnetic field lines connect to the plasmasphere, a torus of plasma in the inner magnetosphere that is both fed by and feeds into the upper ionosphere (e.g., Evans and Holt 1978). Light ions (primarily $\mathrm{H}^{+}$) are the dominant constituents transported between the ionosphere and plasmasphere, which is typically directed upwards into the plasmasphere during the day and downwards into the ionosphere at night. However, during solstice seasons interhemispheric transport has been observed at night, transporting plasma from the summer hemisphere into the winter hemisphere at night. During low levels of solar activity this interhemispheric transport has been seen after sunset, but at high levels of solar activity it usually only occurs after midnight (Evans and Holt 1978; Kersley et al. 1978).

Mars does not have a global-scale internal magnetic field (Acuña et al. 1999), and as a consequence the ionosphere is the main part of the upper atmosphere that directly interacts with the solar wind. However, some areas over the Martian surface are magnetized (the so-called crustal magnetic fields) and their intensity can reach tens of nT at $300 \mathrm{~km}$ altitude. Although the strength of these localized Martian magnetic fields are much weaker than the terrestrial magnetic fields, they do shield portions of the planet from direct interactions with the solar wind. They create, in essence, multiple miniature magnetospheres that exhibit many of the same behaviours that are seen in high latitudes at Earth, such as aurora (e.g., Bertaux et al. 2005; Brain et al. 2010). The most intense crustal fields are located in the southern hemisphere between $120^{\circ}$ and $240^{\circ}$ longitude in horizontal bands of different polarities (e.g., Cain et al. 2003). The inclination of these fields has an important effect on the Martian TEC, such that the TEC is enhanced over quasivertical crustal magnetic fields, and reduced over quasihorizontal crustal magnetic fields (Němec et al. 2010; Cartacci et al. 2013). These enhancements are related to changes in the scale height of the ionosphere, possibly caused by heating of the ionosphere by solar wind electrons that reach low ionospheric altitudes along the nearly vertical (open) magnetic field lines (e.g., Duru et al. 2006). Because crustal fields are localized, large scale transport processes (such as the terrestrial high-latitude plasma convection and low-latitude EIA) cannot occur. 
Nevertheless, day-to-night ionospheric transport plays an important role in the Martian ionosphere. Crossterminator transport affects Martian ion losses through escape processes (e.g., Kar et al. 1996), with the oxygen loss rate from ion transport making up $5 \%$ of the total oxygen loss rate (e.g., Cravens et al. 2017) depending on the solar activity level ( e.g., Fox 1997, 2009), the ambient magnetic pressure, and the crustal magnetic field orientations (e.g., Wu et al. 2019). These ion losses are potentially important at Mars for the evolution of volatiles.

\section{Solar wind interaction}

The lack of a global intrinsic planetary magnetic field at Mars (and the presence of such a magnetic field at Earth) also cause differences in the way each planet interacts with the solar wind. As mentioned in the previous section, the terrestrial magnetic field extends far beyond the terrestrial surface and atmosphere to form a magnetosphere that interacts with the solar wind. This interaction shapes much of the characteristics of the magnetosphere, causing the formation of a bow shock, an upstream foreshock, a magnetosheath, a magnetotail, and an inner magnetosphere. At Earth, these regions contain plasma from both the solar wind and the Terrestrial atmosphere, with the solar wind providing a large amount of ionised hydrogen (e.g., Welling et al. 2015).

Mars also has a magnetosphere with the same basic characteristics as the Terrestrial magnetosphere. However, the magnetospheric plasma is primarily of atmospheric origin, since the Martian ionosphere acts as the primary obstacle for the solar wind (Halekas et al. 2017). The relationship between the thermal pressure of the ionosphere and the solar wind dynamic pressure varies with the solar cycle (Sánchez-Cano et al. 2016), and it delimits the location of the Martian bow shock, which is more sensitive to variations in the solar irradiance than to solar wind dynamic pressure variations (Hall et al. 2016b). Because of this relationship, the solar wind is able to induce an horizontal magnetic field on the dayside ionosphere of Mars (e.g., Shinagawa and Cravens 1989; Ramírez-Nicolás et al. 2016), the magnitude of which is controlled by the strength of the ionosphere. Since the ionospheric strength varies with the solar cycle, there is a larger probability for a more magnetized ionosphere during low solar activity periods (Sánchez-Cano et al. 2015a, 2016). The Mars-solar wind interaction causes the IMF carried by the solar wind to drape around the planet, forming the Martian induced magnetosphere. The localized crustal magnetic fields also contribute to the magnetosphere, though their contributions perturb the bow shock and magnetosheath structure formed by the IMF. The crustal field-ionosphere-solar wind interaction is very complex, producing large ionospheric variability (e.g., Mazelle et al. 2004; Brain et al. 2005; Edberg et al. 2008; Cartacci et al. 2013; Hall et al. 2016a).

\section{Thermosphere}

The Terrestrial and Martian thermospheres make up the upper portion of the planetary neutral atmospheres, extending from the mesopause to the exobase. These thermospheres are both characterized by a temperature gradient that increases with increasing altitude, at first rapidly before slowing to asymptotically reach the exobase temperature. Both thermospheres are strongly impacted by coupling from above (through solar radiation, solar wind particles, and electric fields) and below (through atmospheric gravity waves, planetary waves and tides, and lower atmospheric weather) (e.g., Meriwether 1983; Wang and Nielsen 2003; Bougher et al. 2004, 2006; Lühr et al. 2007; Withers 2009; Emmert et al. 2010; Eckermann et al. 2018; Sánchez-Cano et al. 2018; Gupta et al. 2019). The majority of both planetary ionospheres also form within their respective thermospheres.

As weakly ionised plasmas, the Terrestrial and Martian ionospheres are highly coupled with their thermospheres. The ionised species are drawn from the local neutral species and created through photoionisation, precipitating particles, and ion-neutral photochemical reactions. The structures of both ionospheres are affected by the differences in the neutral species, the temperature of the planetary atmosphere, and dynamical processes in the thermosphere.

Although conceptually similar, the details of the Martian and Terrestrial thermospheres cause important differences between their ionospheres. At Mars, the major thermospheric species $\left(\mathrm{CO}_{2}, \mathrm{O}, \mathrm{N}_{2}\right.$, and $\left.\mathrm{CO}\right)$ lead to an ionosphere that is dominated by $\mathrm{O}_{2}^{+}$. At Earth, the major thermospheric species $\left(\mathrm{O}, \mathrm{O}_{2}, \mathrm{~N}\right.$, and $\left.\mathrm{N}_{2}\right)$ lead to an ionosphere that is dominated by $\mathrm{O}^{+}$at the ion density peak. This results in an important difference between the Terrestrial and Martian ionospheres: at Mars the major species are lost through one-stage recombination processes, but at Earth $\mathrm{O}^{+}$is lost through a slower, two-stage process involving reactions with both $\mathrm{N}_{2}$ and $\mathrm{O}_{2}$ (Schunk and Nagy 2009).

The thermospheric composition also means that both ionospheres are affected by EUV irradiance. Although the Earth and Mars are sensitive to slightly different wavelengths within the EUV range (discussed in more detail in the Section "TIMED/SEE EUV"), their variations on short and long scales are similar. Thus, photochemical ionospheric layers in both the Terrestrial and Martian ionospheres have been shown to react with magnitudes proportional to their distance from the Sun (Mendillo et al. 2003). 
Both planets have ion density anomalies that are tied to the neutral atmosphere. At Earth the semi-annual anomaly, characterized by thermospheric and ionospheric densities that are higher than expected at equinox and lower then expected at solstices. This can be explained by global neutral atmospheric circulation in the mesosphere and thermosphere that affects the ionosphere through changes in the O: $\mathrm{N}_{2}$ ratio (Fuller-Rowell 1998; Jones et al. 2018). There are also seasonal and annual anomalies that are characterized by higher mid-latitude peak ion densities in the winter than the summer hemisphere (Yonezawa 1959) and a higher level of ionospheric plasma density during northern hemisphere $(\mathrm{NH})$ winter/southern hemisphere $(\mathrm{SH})$ summer (the December solstice) than $\mathrm{NH}$ summer/SH winter (the June solstice) (Yonezawa and Arima 1959), respectively. The seasonal anomaly is again understood to be caused by changes in the thermospheric composition, affecting the ionosphere by altering the O: $\mathrm{N}_{2}$ ratio (e.g., Fuller-Rowell et al. 1988). The smaller annual anomaly (or annual asymmetry) is still an area of active investigation (e.g., Azpilicueta et al. 2011).

At Mars, a large increase in global plasma density is observed at $\mathrm{L}_{S}=230^{\circ}$ (Northern autumn and Southern spring). This increase is related to a warmer and thicker thermosphere (seasonal atmospheric expansion), which is caused by the orbital eccentricity that places Mars closer to the Sun at this time. Moreover, the $\mathrm{CO}_{2}$ sublimation of the South polar cap at the surface and lower atmosphere contributes to a plasma increase during these seasons. The influence of the $\mathrm{CO}_{2}$ on the thermosphere is also notable at $\mathrm{L}_{S}=40^{\circ}$ (Northern spring and Southern autumn), when the North polar cap sublimation increases the plasma, as shown in Fig. 4. However, the increase is smaller in this case because Mars is further position from the Sun than it was at $\mathrm{L}_{S}=230^{\circ}$. Simulations suggest that this increase in plasma density is caused by the sublimation of $\mathrm{CO}_{2}$ at the surface and lower atmosphere that increases the $\mathrm{O}, \mathrm{O}_{2}$, and $\mathrm{N}_{2}$ populations in the thermosphere. As discussed above, these populations are sources for the major ionospheric species and so lead to an increase in the global TEC as discussed by Sánchez-Cano et al. (2018), and also seen by other authors (Bergeot et al. 2019).

The ionospheres at both planets also experience a large degree of daily variability due to interactions with the lower atmosphere. Many of these lower atmospheric drivers are the same, though the coupling processes and affects differ. For example, both planets are affected by gravity waves (Yiğit et al. 2009, 2015) and the influences of topography (Wang and Nielsen 2004; Immel et al. 2006). However, at Earth coupling between the lower atmosphere and upper ionosphere often occurs through electric fields that map along magnetic field lines and are driven by currents created through interactions between the neutral atmosphere, ionosphere, and magnetic field at lower altitudes.

Another important source of coupling between the lower atmosphere and ionosphere is through tropospheric weather events. At Mars, dust storms are huge events that can encompass the entire planet. These storms introduce particles into the lower atmosphere that heat the lower atmosphere by radiative transfer. This produces a subsequent thermal expansion of the lower atmosphere that lifts pressure levels in the upper atmosphere, lifting also the ionosphere ( e.g., Withers 2009). Effects of seismic disturbances and tropospheric weather also exist at Earth, but their impacts are weaker than the other processes discussed here in more detail (e.g., Occhipinti et al. 2008; Kartalev et al. 2004; Goncharenko et al. 2010; Ogawa et al. 2012; Frissell et al. 2016).

\section{Data}

This study uses measurements of solar EUV irradiance and TEC to examine and compare the ionospheres at Earth and Mars over a period of time beginning during the descending phase of the $23^{\text {rd }}$ solar cycle and ending during solar maximum of the $24^{\text {th }}$ solar cycle. Although a simple measure of ionospheric column density, the TEC has been used to study many 'anomalies' caused by unknown (at least at the time of their naming) interactions in the upper atmosphere (e.g., Azpilicueta et al. 2011). For both planets, the TEC are provided in TEC units (TECU), where 1 TECU $=10^{1} 6 \mathrm{e}^{-} \mathrm{m}^{-} 2$. Empirical and first principles models are also used when measurements are lacking and physical insight into the observed characteristics are needed, respectively. These measured and modeled data sources are described in the following subsections.

\section{GNSS TEC}

The TEC at Earth is measured using transmissions from Global Navigation System Satellite (GNSS) receivers, which detect signals from the Global Positioning System (GPS), the Global Navigation Satellite System (GLONASS), and Galileo satellite constellations processed at MIT Haystack and provided by the CEDAR Madrigal database (Rideout and Coster 2006). This vertical TEC and its uncertainty are provided at a $1^{\circ}$ latitude $\times 1^{\circ}$ longitude resolution in geographic coordinates every second from 1998 onward. Coverage is provided from all publicly available ground and space-based receivers. Figure 2 shows the available coverage of the ionospheric pierce points at a $1^{\circ}$ latitude $\times 1^{\circ}$ longitude resolution for a day near the beginning and end of this study. 


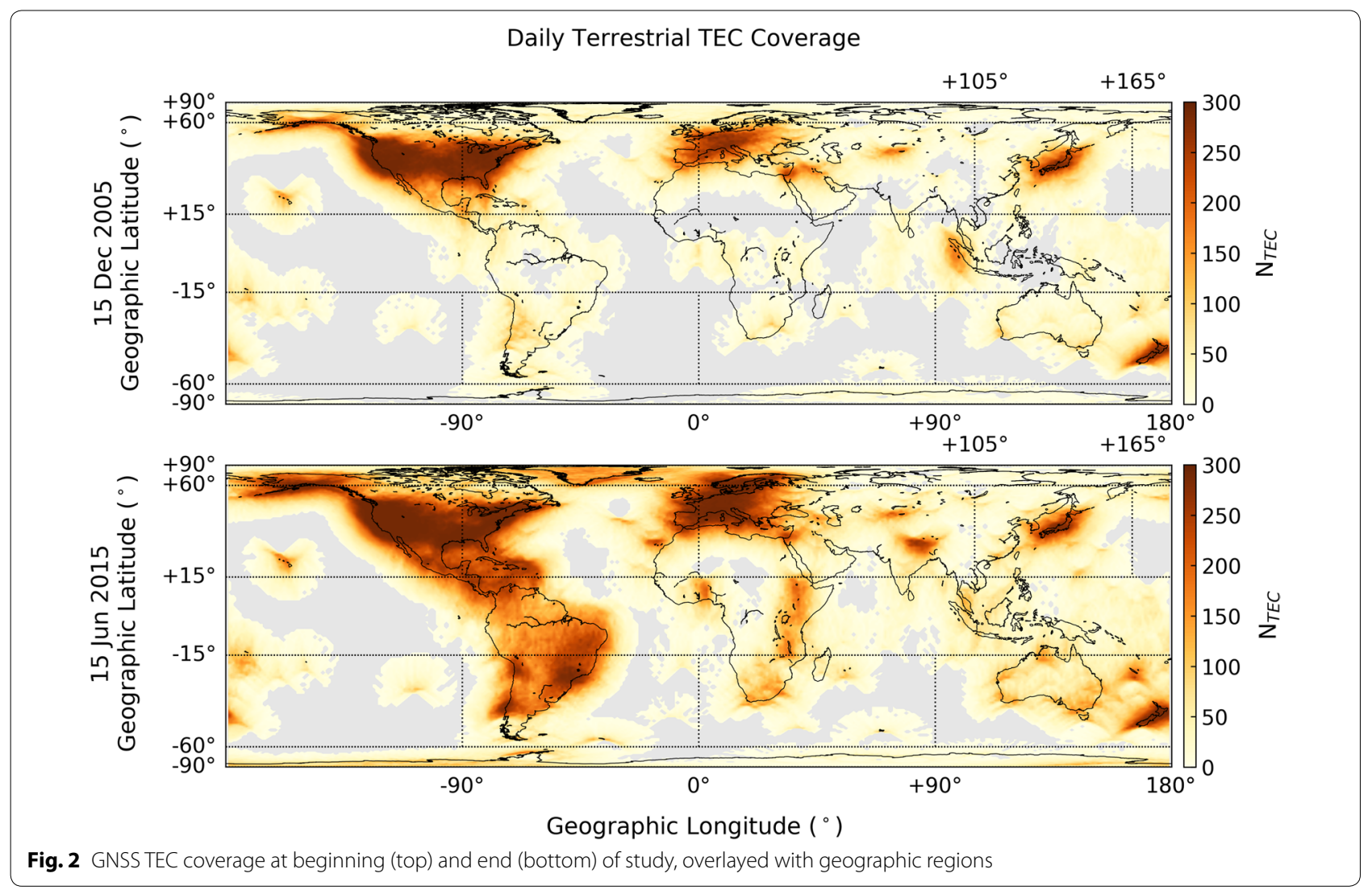

\section{MARSIS TEC}

The Mars Advanced Radar for Subsurface and Ionosphere Sounding (MARSIS) radar (Picardi et al. 2004; Orosei et al. 2015) on board Mars Express (Chicarro et al. 2004) has been sounding the planet since mid-2005, currently covering a full solar cycle of observations. MARSIS can be run in two different operational modes:

(1) The Active Ionospheric Sounding (AIS) mode (Gurnett et al. 2005), a topside ionospheric sounder that measures topside electron density, from which the topside TEC can be obtained.

(2) The subsurface mode, in which the radar sounds the surface and subsurface of the planet to measure materials beneath the surface of the planet.

In the second mode, the TEC of the entire atmosphere is retrieved as a by-product of the signal distortion analysis (Safaeinili et al. 2007; Mouginot et al. 2008; Cartacci et al. 2013, 2018).

This study is limited to MARSIS data from the subsurface operational mode. The TEC was obtained through the Cartacci et al. (2013) algorithm, after selecting for data with a Signal-to-Noise Ratio (SNR) larger than 20
$\mathrm{dB}$ and carrier frequencies of 4 and $5 \mathrm{MHz}$. This conservative approach of using only strong signals measured at higher frequencies guarantees a good data quality. However, because the carrier frequencies are very close to the maximum plasma frequency of the Martian dayside ionosphere $(\sim 3 \mathrm{MHz})$, the radar cannot work on the proper Martian dayside. This limits the TEC observations to SZA > 50-60 ${ }^{\circ}$ Sánchez-Cano et al. 2015b). Moreover, due to the evolution of the Mars Express orbit and observation planning priorities, there is a large asymmetry on the amount of data collected between dawn and dusk sectors, being on average for the full mission of $\sim 88 \%$ larger for the dusk sector (Sánchez-Cano et al. 2018). Note, as well, that typically $\sim 70 \%$ of the electron density contribution to the TEC is obtained from the region near the height of maximum ionisation in the ionosphere (photochemical region) (e.g. Sánchez-Cano et al. 2013), and so is an excellent indicator of the variability of the photochemical region of the ionosphere (e.g. Mendillo et al. 2015).

\section{TIMED/SEE EUV}

The Solar EUV Experiment (SEE) is one of four scientific instruments flying onboard the NASA Thermosphere Ionosphere Mesosphere Energetics Dynamics (TIMED) 
satellite. TIMED/SEE measured the solar irradiance from 0.1 to $194 \mathrm{~nm}$. In the higher level data products, the observations are adjusted to reflect the solar irradiance at 1 AU (Woods et al. 2005).

Figure 3 shows two different measures of solar irradiance obtained from TIMED/SEE data. The top panel shows the $30.5 \mathrm{~nm}$ irradiance scaled to the Mars heliocentric distance following an inverse-square law and assuming no significant differences in solar longitude between Earth and Mars. This wavelength is typically used at Mars since it is responsible for the majority of the photoionisation (Rishbeth and Mendillo 2004). The bottom panel shows the $\mathrm{O}^{+}$power at Earth, calculated based on the process outlined in Richards et al. (1994). This measure of EUV irradiance was chosen because $\mathrm{O}^{+}$is the dominant ion in the $\mathrm{F}$ region.

\section{Horizontal wind model}

Neutral winds play an important role in the Terrestrial $F$ region ionosphere, as noted in the Section "Thermosphere". However, these winds are difficult to measure.
This study uses data from the Horizontal Wind Model (HWM) instead of observations (Drob et al. 2015). The HWM incorporates observations from many overlapping and disparate, ground- and space-based data sets. The resulting model uncertainties reflect the natural variability of the winds, the uncertainties of the observational data, and the spatiotemporal coverage of the observational data. HWM captures variations due to geographic location, time of day, and time of year. Solar cycle variations are not modeled, due to insufficient data coverage. Additionally, high altitude thermospheric winds (above $250 \mathrm{~km}$ ) are not routinely measured and so the model is not as trustworthy at these heights.

\section{Mars climate database}

The Mars Climate Database (MCD) Version 5.3 is a data base of meteorological parameters obtained from a general circulation model of the Martian atmosphere (Forget et al. 1999; Millour et al. 2018). These meteorological parameters, which include (but are not limited to) atmospheric temperature, density, pressure, and winds, have been validated against available observational data

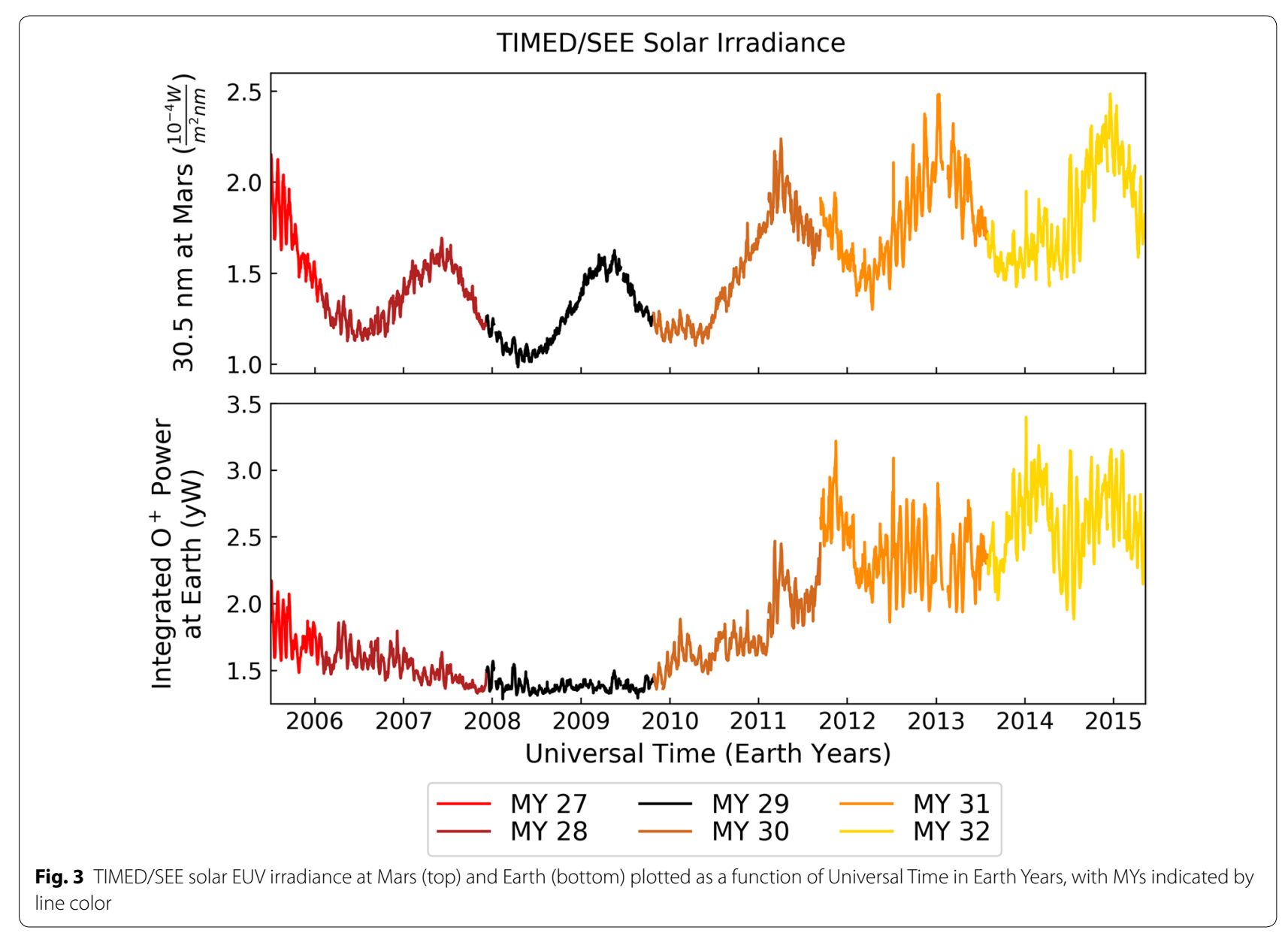


and are freely available upon request or through a simple online interface. This study uses the neutral temperature and density near the ionospheric peak altitude to examine the influence of the Martian thermosphere on the ionosphere.

\section{Analysis}

Due to the differences in the length of year, orbital eccentricity, and thermospheric interactions, ionospheric density comparisons between the Martian and Terrestrial ionospheres are difficult. To permit comparisons, this study considers different ratios of the rate of change of TEC as a function of SZA for several spatiotemporal regions. The spatiotemporal regions are discussed in the Section "Data selection" and the method used to obtain the rate of change of TEC as a function of SZA is discussed in the Section "Linear fitting".

\section{Data selection}

Data selection in this study uses both Martian and Terrestrial conventions, as deemed appropriate. Data are grouped by Martian Year (MY) (and limited to the period of time when Martian TEC is available to ensure a similar coverage), but seasons are centered about the solstices, as is the custom at Earth. The seasons for each MY span the solar longitudes $\left(\mathrm{L}_{S}\right)$ shown in grey boxes in Fig. 4. $\mathrm{NH}$ summer/SH winter contains data with $25^{\circ}<L_{S}<155^{\circ}$, while $\mathrm{NH}$ winter/SH summer contains data with $205^{\circ}<L_{S}<335^{\circ}$. The seasonal range was chosen to improve planetary coverage at Mars and include data with similar solar irradiance conditions, as shown in Fig. 4. Note that the $\mathrm{NH}$ summer/SH winter season happens when both Earth and Mars are furthest from the Sun, with $\mathrm{NH}$ winter/SH summer occurring when the two planets are closest to the Sun. This causes an additional variation in the amount of solar irradiance for each season that is much smaller at Earth than it is at Mars. Moreover, the data have been divided up by MY instead of EUV flux levels to focus on the study of the annual seasonal variations. This has the additional benefit of separating data into different phases of the solar cycle, as each MY spans at most one phase (ascending, maximum, descending, or minimum) of the solar cycle.

The spatial regions were chosen to provide similar seasonal and magnetic environments. At Mars, this means that the Northern and Southern hemispheres are divided at the equator and the Southern hemisphere is further divided into longitudes $(\lambda)$ with $\left(150^{\circ} \leq \lambda<270^{\circ}\right)$ and without $\left(-120^{\circ} \leq \lambda<150^{\circ}\right)$ crustal magnetic fields. At Earth, eight mid-latitude regions are selected, as shown in Fig. 1. High latitudes were not considered to reduce the influence of magnetosphere-ionosphere interactions. Low latitudes were excluded to reduce the influence of the plasma transport that forms the EIA. The eight midlatitude regions were chosen to encompass similar magnetic field orientations and strengths, as shown in the top and bottom panels of Fig. 1. Four SZA regions were chosen based on the location of the solar terminator. To separate data before and after noon, SZAs before noon are labeled with negative values and those after noon remain positive. At each planet, the location of the solar terminator was calculated at different important altitudes (such as the typical height of the ion density peak). This informed the SZA regions shown in Table 1. Note that Earth is more restrictive than Mars, because the wealth of available data made it possible to remove SZAs that encompass the period of time when the solar terminator enters and exits the $\mathrm{F}$ region.

\section{Linear fitting}

Linear fits to the TEC in each year, season, location, and SZA region are made to determine the typical behavior of the TEC as a function of SZA and aid in the comparison between this behavior at Mars and at Earth. Due to the large amount of variability in this data and the existence of outliers, a robust linear regression method known as the Huber method was used (Huber 1963). This method considers the influence of outliers without allowing their presence to dominate the regression by identifying the outliers and applying a linear loss to those samples when performing the linear regression. The Python implementation of this method, sklearn.linear_model.HuberRegressor, was used in the Terrestrial portion of this study (Pedregosa et al. 2011), while the MatLab implementation was used for the Martian data (The MathWorks, Inc. 2019). An example of how the Huber Regressor method performs on the Martian and Terrestrial TEC is shown in Fig. 5. The difference between standard linear and Huber regressions are shown in panel (a), highlighting the way that outliers can overly influence a standard linear fit. The selection of outliers and inliers is highlighted for the Terrestrial data in panel (b); note that the spread of the inliers changes in each SZA region based on the distribution of TEC in that region. Panels (c-f) show both how the Huber method selects the most representative data as inliers, and how well the Huber fit represents the distribution of the data in the selected SZA region. The Huber fit slopes and intercepts, as well as the medians and quartiles of the differences between the dawn and dusk Huber fits and the TEC observations for each planet, region, and MY are included in Additional file 1. The small medians and symmetric upper and lower quartiles $\left(\mathrm{q}_{3}\right.$ and $\mathrm{q}_{1}$ respectively) provide confidence in the Huber slopes and intercepts. 


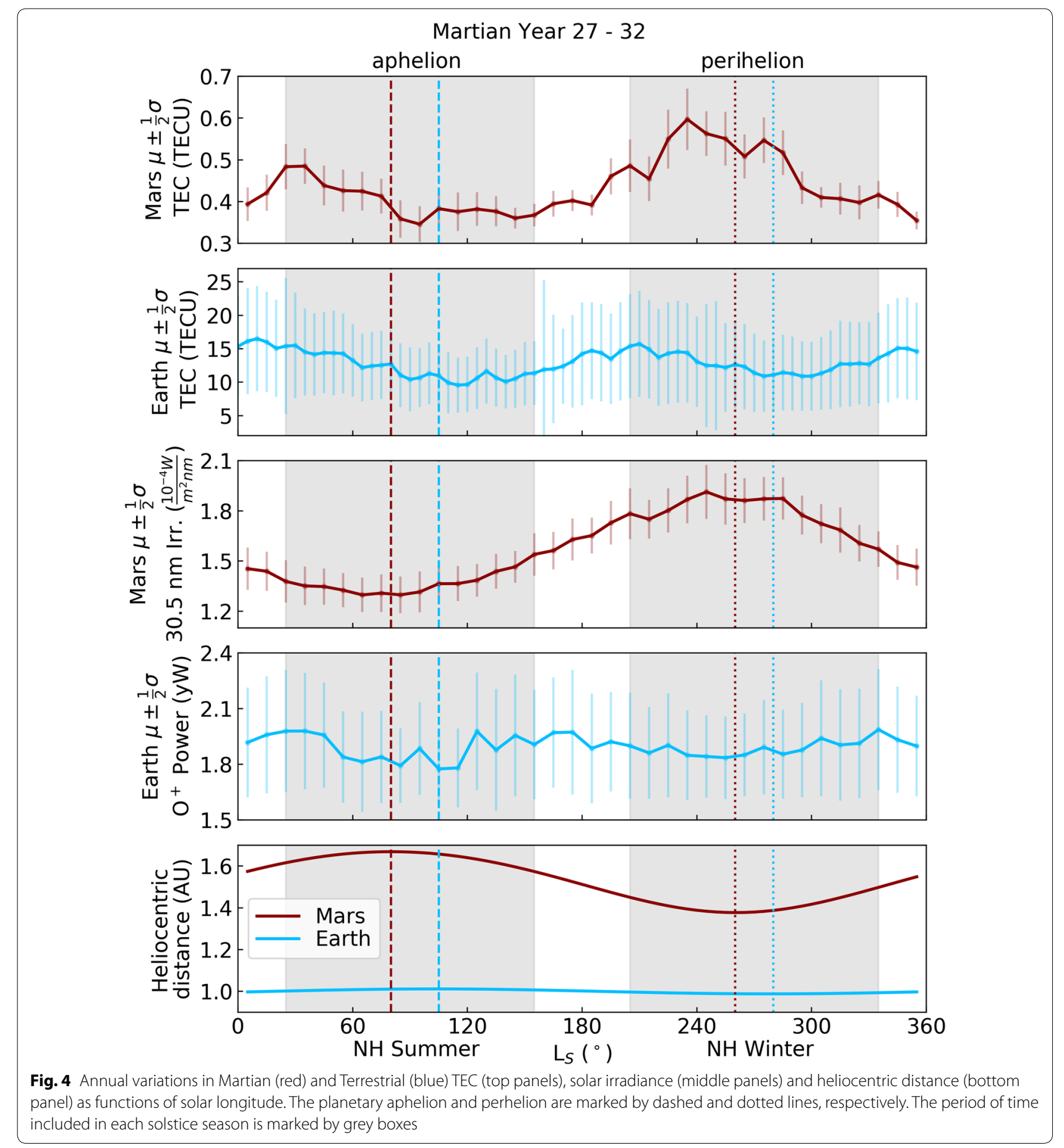

Table 1 SZA regions at Mars and Earth

\begin{tabular}{lll}
\hline SZA region & Earth & Mars \\
\hline Pre-dawn & $-135^{\circ} \leq S Z A \leq-110^{\circ}$ & $-135^{\circ} \leq S Z A<-105^{\circ}$ \\
Dawn & $-102^{\circ} \leq S Z A \leq-50^{\circ}$ & $-105^{\circ} \leq S Z A \leq-50^{\circ}$ \\
Dusk & $50^{\circ} \leq S Z A \leq 102^{\circ}$ & $50^{\circ} \leq S Z A<105^{\circ}$ \\
Night & $110^{\circ} \leq S Z A \leq 135^{\circ}$ & $105^{\circ} \leq S Z A \leq 135^{\circ}$ \\
\hline
\end{tabular}

\section{Results and discussion}

\section{Martian TEC}

This section focuses on the morning and afternoon sectors (dawn and dusk slopes, SZAs up to $\pm 105^{\circ}$ ) of the photochemical region of the ionosphere. This is because most of the Martian TEC is obtained from the region where plasma is near and above the height 


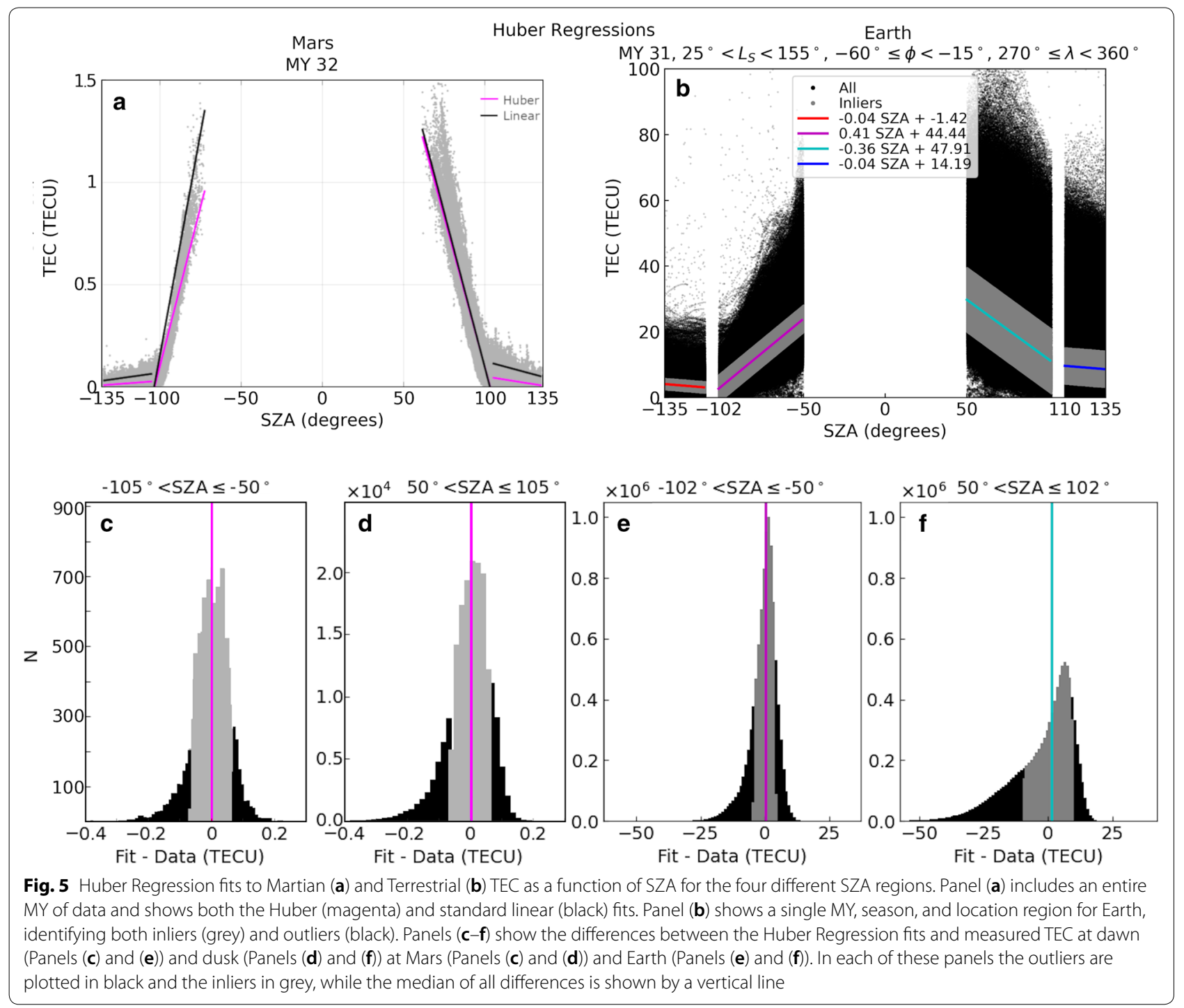

of maximum electron density of the ionosphere (e.g., Mendillo et al. 2015). In this region, plasma is controlled by a photochemical equilibrium, meaning that production via photoionisation and losses via recombination tend to be equal. Nevertheless, there are other processes that dominate at higher altitudes (typically above $\sim 200 \mathrm{~km}$ ) for all SZAs, such as vertical transport (e.g., Chen et al. 1978; Mendillo et al. 2011; Kar et al. 1996; Fox 1997, 2009; Cravens et al. 2017; Wu et al. 2019, ), which are not investigated in this study because their contribution to the TEC is smaller. In addition, at high SZAs and far from crustal field regions, dayto-night plasma transport plays an important role in shaping the Martian ionosphere near and beyond the terminator (e.g.,Němec et al. 2010; Withers et al. 2012; Cui et al. 2015; Girazian et al. 2017; Cao et al. 2019).
Plasma transport into the nightside is not investigated in this study, although it should be noted that the low TEC values beyond $90^{\circ} \mathrm{SZA}$ should be affected by this process (e.g., Cui et al. 2015; Cao et al. 2019).

The Huber fits to Martian TEC as a function of SZA in the four SZA regions are shown in Fig. 6 for the three location regions, both solstices, and each MY. The MYs are color coded such that darker colors indicate lower levels of solar activity, though the amount of irradiance in each MY varies based on the heliocentric distance, as previously shown in Fig. 3. Due to coverage constraints, not all regions have Huber fits every MY. Coverage is greater at dusk than dawn, and is worst in the pre-dawn region (motivating this study consider only dusk and dawn in depth). 


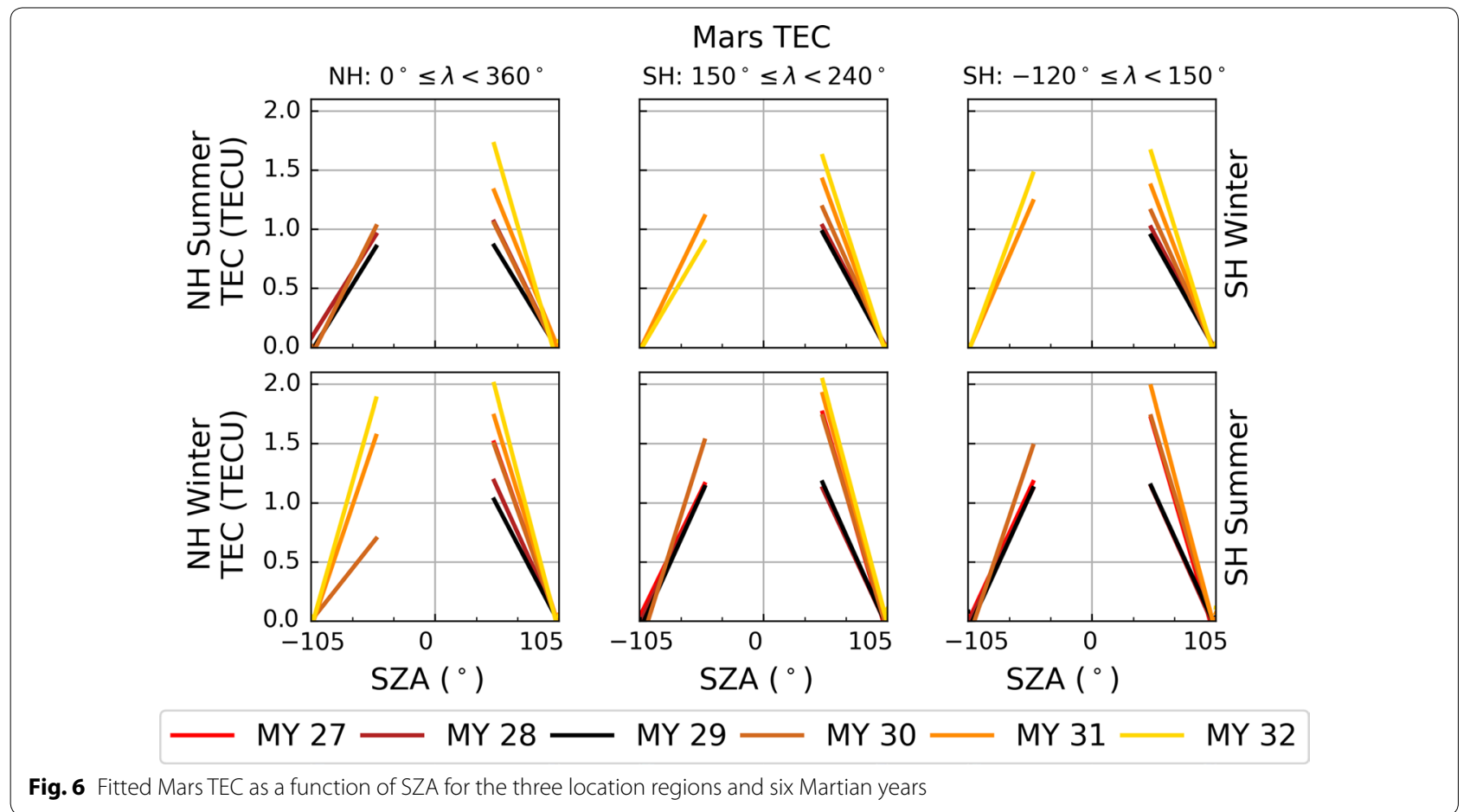

Despite these constraints, it is apparent that the TEC slopes increase in magnitude as solar activity increases, for all location regions and seasons. This behavior is similar for the dawn and dusk slopes, as is expected for an ionosphere dominated by photochemical processes. The similarities between the TEC slopes indicate that the presence of crustal magnetic fields have a localized influence that does not affect the regional production via photoionisation and loss via recombination processes.
Comparing the top row (NH summer and $\mathrm{SH}$ winter) to the bottom row (SH winter and $\mathrm{SH}$ summer) demonstrates that heliocentric distance greatly affects the production of TEC. Regardless of the season in that hemisphere, the maximum levels of TEC are higher in the bottom panel than they are in the top panel. Figure 7 examines this in more detail, by taking the summer:winter ratio of the dusk TEC slopes for each location region and MY. Dawn summer:winter ratios

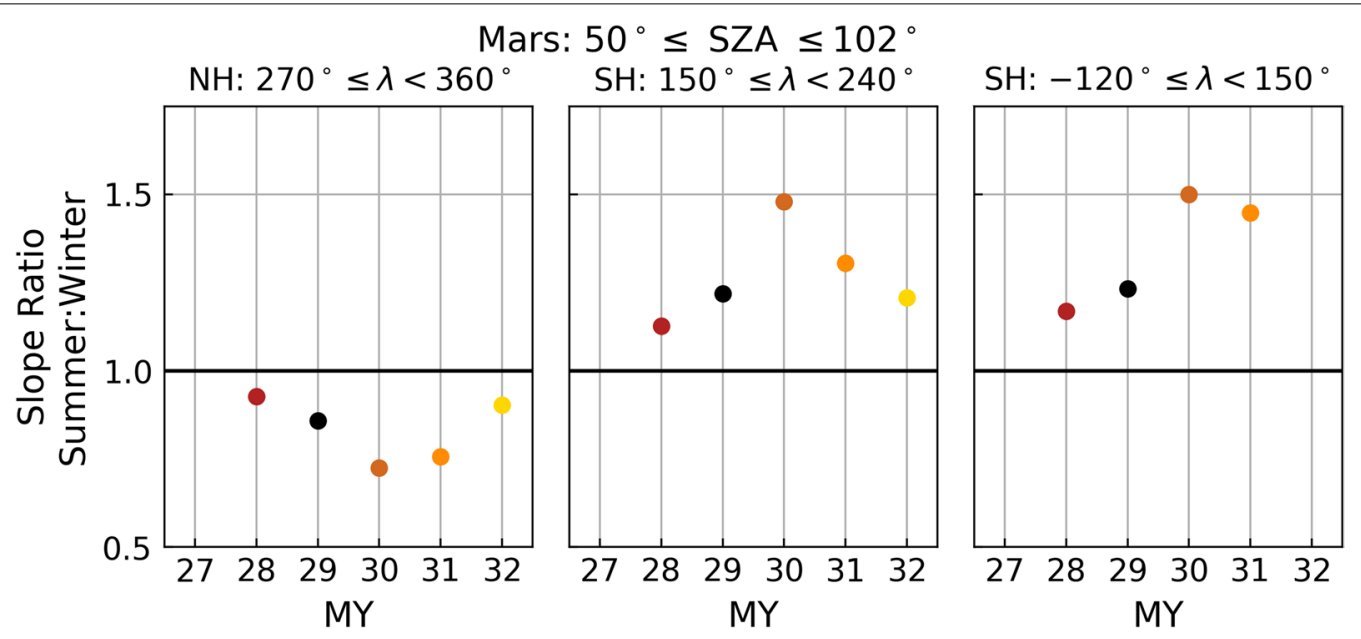

Fig. 7 Ratio between the summer and winter Martian dusk slopes for TEC as a function of SZA for the three location regions and six Martian years 
were not examined, due to the constraints on coverage over the solar cycle.

Figure 7 clearly shows that heliocentric distance has a greater influence on the rate of ionospheric plasma production via photoionisation and loss via recombination, as greater loss rates (as captured by the dusk TEC slope) occur during $\mathrm{NH}$ summer and $\mathrm{SH}$ winter over the entire planet. This hemispheric difference in the seasonal variation (as indicated by a ratio less than unity in the $\mathrm{NH}$ and greater than unity in the $\mathrm{SH}$ ) can be attributed to a combination of the orbital impact on photoionisation rates and the neutral atmospheric density (as discussed in the Planetary size and orientation and Section "Thermosphere").

To assess the impact of neutral atmosphere on the hemispheric differences in the dusk seasonal variation, atmospheric variations in density and temperature were retrieved from the MCD (see the Section "Mars climate database") for both solstices at mid-latitude locations in the $\mathrm{NH}$ (longitude of $0^{\circ}$ ), $\mathrm{SH}$ over crustal fields (longitude of $180^{\circ}$ ), and $\mathrm{SH}$ without crustal fields (longitude of of $0^{\circ}$ ), as shown in Fig. 8. This figure plots the neutral temperature (black) and density (blue) at $135 \mathrm{~km}$ above the reference level (called "sea level" at the MCD) as a function of SZA. Each column shows a different aerographic region during the $\mathrm{NH}$ summer/SH winter (top row) and the $\mathrm{NH}$ winter/SH summer (bottom row). Comparing the global densities in the $\mathrm{NH}$ summer (top row) and SH summer (bottom row) reveals that neutral densities at ionospheric altitudes are higher in both hemispheres during SH summer (bottom row) than in $\mathrm{NH}$ summer (top row). Thus, both the direct influence of a decrease in photoionisation rates due to distance and a change in the neutral atmospheric density lead to summer:winter ratios that are less than unity in the $\mathrm{NH}$ and greater than unity in the $\mathrm{SH}$.

Figure 7 also reveals the strong modifying influence of the solar cycle on the summer:winter ratio. MYs with large changes in solar activity, most notably MY 30 (which occurred during the end of the low solar activity phase and the ascending phase of the $23^{\text {rd }}$ solar cycle), are characterized by seasonal ratios that deviate most from unity. The hypothesis that the changes in solar cycle over the course of MY 30 are causing the most extreme seasonal ratios in Fig. 7 was tested using the NeMars model (Sánchez-Cano et al. 2013, 2016). This model uses $\mathrm{F}_{10.7}$ measured at Earth to capture solar irradiance changes at Mars' heliocentric distance, considers the phase of the solar cycle, and solves for ionospheric density using the Chapman formulation (Chapman 1931). The modeled TEC varying between SZA $50^{\circ}$ and $90^{\circ}$ was calculated for the heliocentric distance of the Martian aphelion (1.66 AU) and perihelion (1.38 AU) for each Martian year (MY27-MY32) and
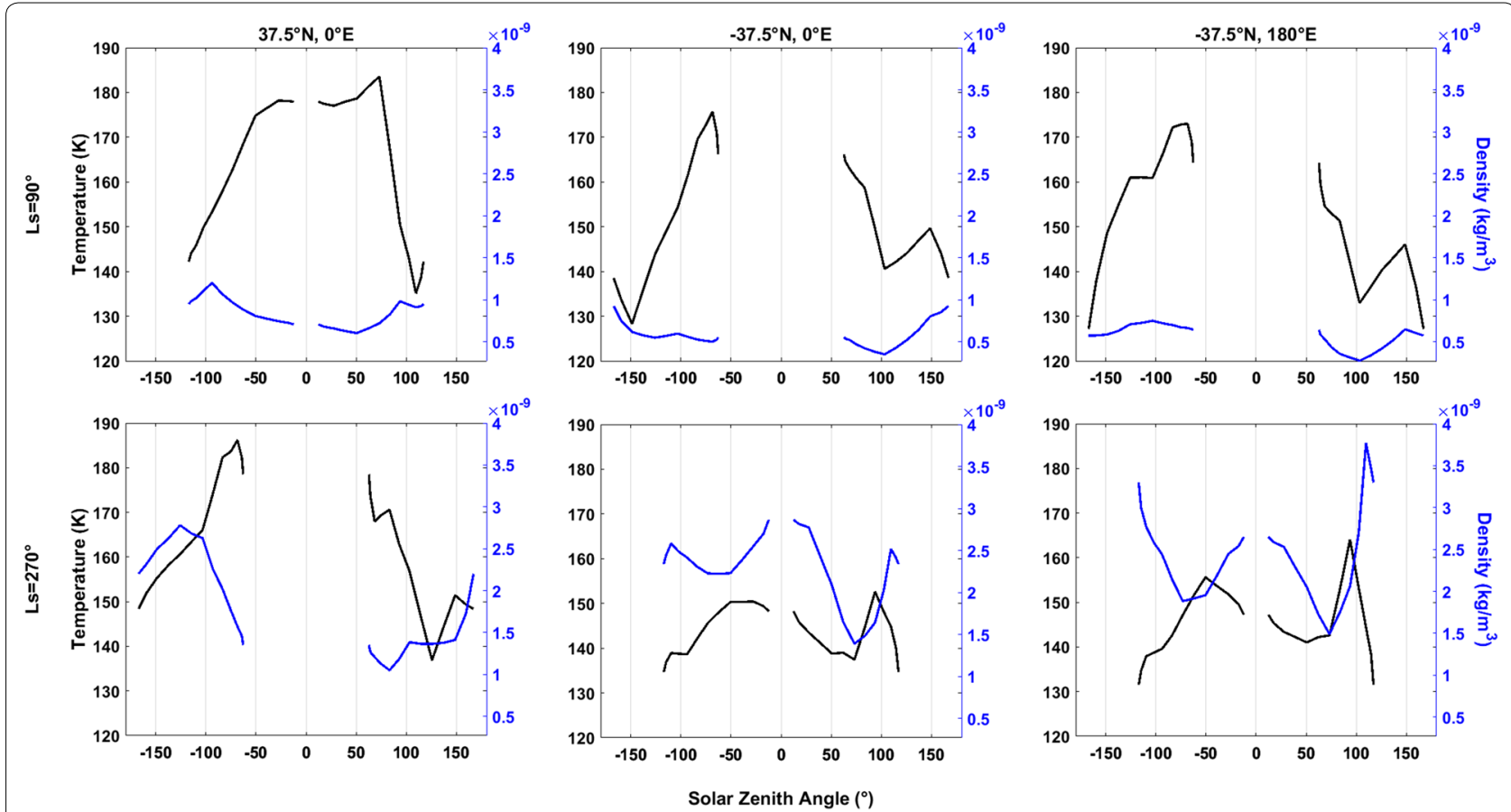

Fig. 8 Modelled neutral atmospheric temperature (black) and density (blue) as a function of solar zenith angle for NH summer/SH winter (top row) and $\mathrm{NH}$ winter/SH summer (bottom row) at locations that fall within the three Martian location regions 
corresponding phase of solar activity. Then, a fit using the Huber Regressor method was performed, similar to the procedure done for the observed data. The results, presented in Figure 9, show a sharp change in the summer:winter sunset slope ratio for MY 30 due to the changes in solar irradiance over this course of the MY.

To summarise, at Mars the rate of change of TEC as a function of SZA at sunrise and sunset are strongly influenced by changes in solar irradiance. The solar cycle has the largest effect (as demonstrated by the changes in dawn and dusk slopes in Fig. 6), followed by heliocentric distance (as demonstrated by the seasonal dusk ratios in

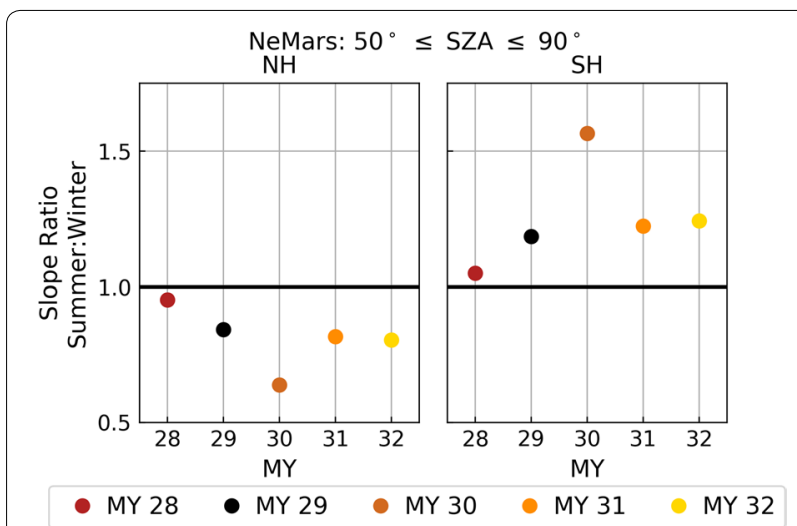

Fig. 9 Ratio between the summer and winter Martian dusk slopes for TEC as a function of SZA for the NH and SH five Martian years using the NeMars model
Fig. 7), and finally season. The presence of crustal magnetic fields may modify the ionosphere locally, but these changes are not evident when considering the entire portion of the $\mathrm{SH}$ dominated by crustal magnetic fields.

\section{Terrestrial TEC}

The Huber fits to Terrestrial TEC as a function of SZA in the four SZA regions are shown in Figs. 10 and 11 for the four longitude regions, both solstices, and each MY in the $\mathrm{NH}$ and $\mathrm{SH}$, respectively. These figures have a similar layout to Fig. 6, with the same color codes for the MYs. As was the case in Fig. 6, the dawn TEC slopes are large and positive following a relatively flat pre-dawn TEC variation with SZA. At dusk and night, however, the TEC variation with SZA is not as consistent.

Figure 10 shows that the northern, winter hemisphere has evening loss rates that are larger at dusk than at night. However, this trend reverses in the summer. One explanation for this behavior is the seasonal anomaly (previously discussed in the Section "Thermosphere"), which changes the $\mathrm{O}: \mathrm{N}_{2}$ ratio so that the ion production via photoionisation and loss via recombination rates are greater in the winter than in the summer (Fuller-Rowell et al. 1988). Increasing the evening ion loss rate reduces the relative importance of $\mathrm{F}$ region sustaining plasma transfer processes, such as plasma transport into the ionosphere from the plasmasphere. Recall that seasonal variations in mid-latitude interhemispheric transport showed plasma transported from the summer hemisphere to the winter hemisphere in the evening (Kersley et al. 1978),

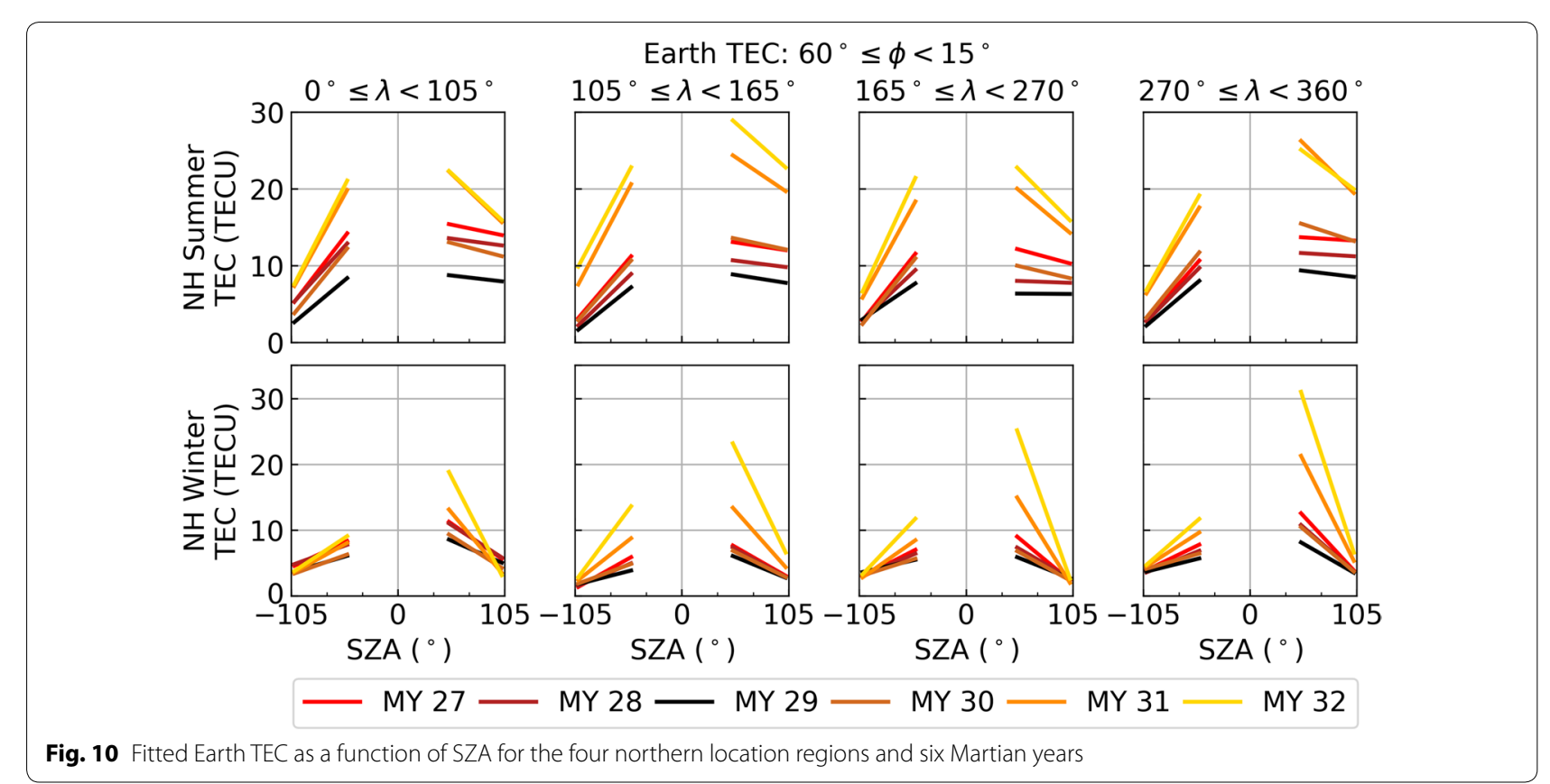




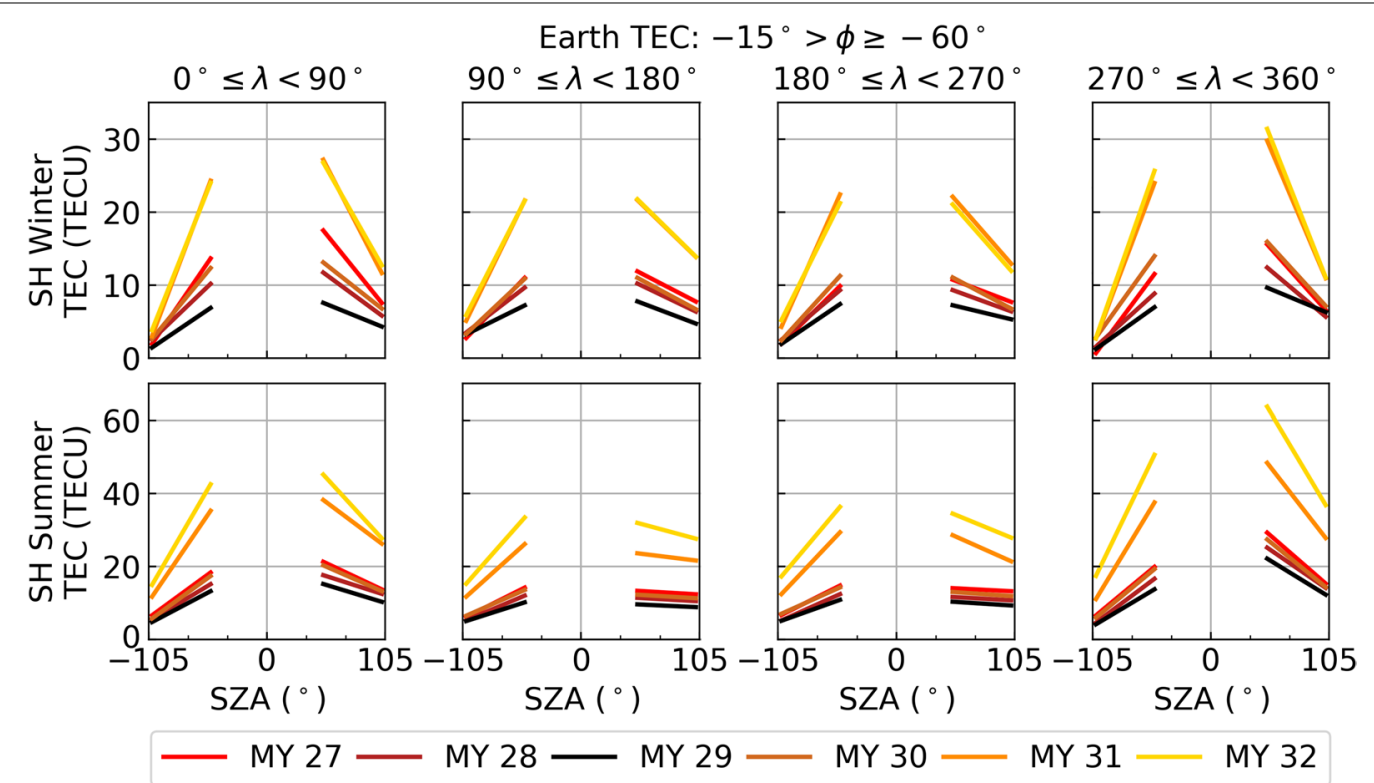

Fig. 11 Fitted Earth TEC as a function of SZA for the four southern location regions and six Martian years

which helps maintain the $\mathrm{F}$ region ionosphere in the winter.

This figure also shows that as the level of solar irradiance increases over the solar cycle, the rate of ion loss, as indicated by the magnitude of the TEC slope, at dusk increases. This again reflects the importance of ionosphere-thermosphere coupling. As the thermosphere expands with increasing solar irradiance, photochemical processes become increasingly important.

This variation is also consistent with the solar cycle variation in mid-latitude interhemispheric transport, which occurs at earlier local times at solar minimum and after midnight at solar maximum (Evans and Holt 1978; Kersley et al. 1978). The existence of this interhemispheric transport points to the presence of upward, field-aligned ionospheric flows in the summer hemisphere that lead to deviations from photochemical equilibrium. When this interhemispheric transport is not present, the midlatitude $\mathrm{F}$ region ionosphere may then be inferred to lie closer to photochemical equilibrium.

Figure 11 shows the same quantities as Figs. 6 and 10, but for the Terrestrial SH regions. The winter TEC at dawn and dusk show greater rates of ion production via photoionisation and loss via recombination, respectively, than their summer counterparts (as was the case in the $\mathrm{NH})$. There are important differences between the two hemispheres, though. The middle rows of Fig. 11 (longitudes between $90^{\circ}$ and $270^{\circ}$ ) show summer and solar cycle behavior similar to that seen in the $\mathrm{NH}$. However, the other longitudes show a TEC dependence on SZA that is more similar to Mars than the Terrestrial $\mathrm{NH}$ (with dawn and dusk slopes of similar magnitude). This behavior is strongest between $270^{\circ}$ and $360^{\circ}$ longitude.

These location regions are characterized by the lowest magnetic field strength and small declination angles. The orientation of the magnetic field modulates the influence of the neutral wind, allowing the horizontal wind to induce field-aligned ion drifts through collisions. Fig. 12 shows the field-aligned component of the HWM14 neutral wind $\left(\mathrm{u}_{\|}\right)$for the December (top) and June (bottom) solstices at dusk $\left(\mathrm{SZA}=70^{\circ}\right)$ for three selected locations (the centers of three of the geographic regions shown in Fig. 1) that represent the typical global variations. This discussion focuses on altitudes between about 150-300 km (typical altitudes of bottomside F region), where $\mathrm{u}_{\|}$plays the largest role in collisionally raising and lowering the plasma density peak. In December, both hemispheres have $\mathrm{u}_{\|}$aligned downward (positive in the north and negative in the south). This is also true in June except at longitudes between $270^{\circ}$ and $90^{\circ}$ (bottom center panel). This is exactly the opposite of what was expected based on the SH TEC slopes, since an upward $\mathrm{u}_{\|}$will raise the $\mathrm{F}_{2}$ peak and inhibit ion loss processes. This implies that the neutral wind does not play a significant role in raising the mid-latitude $\mathrm{F}_{2}$ peak at dusk during the solstices.

The other primary transport mechanism on Earth at the mid-latitudes is the $\mathbf{E} \times \mathbf{B}$ drift. As discussed in the Section "Planetary environments", a positive meridional $\mathbf{E} \times \mathbf{B}$ drift will move the plasma upwards and polewards, 


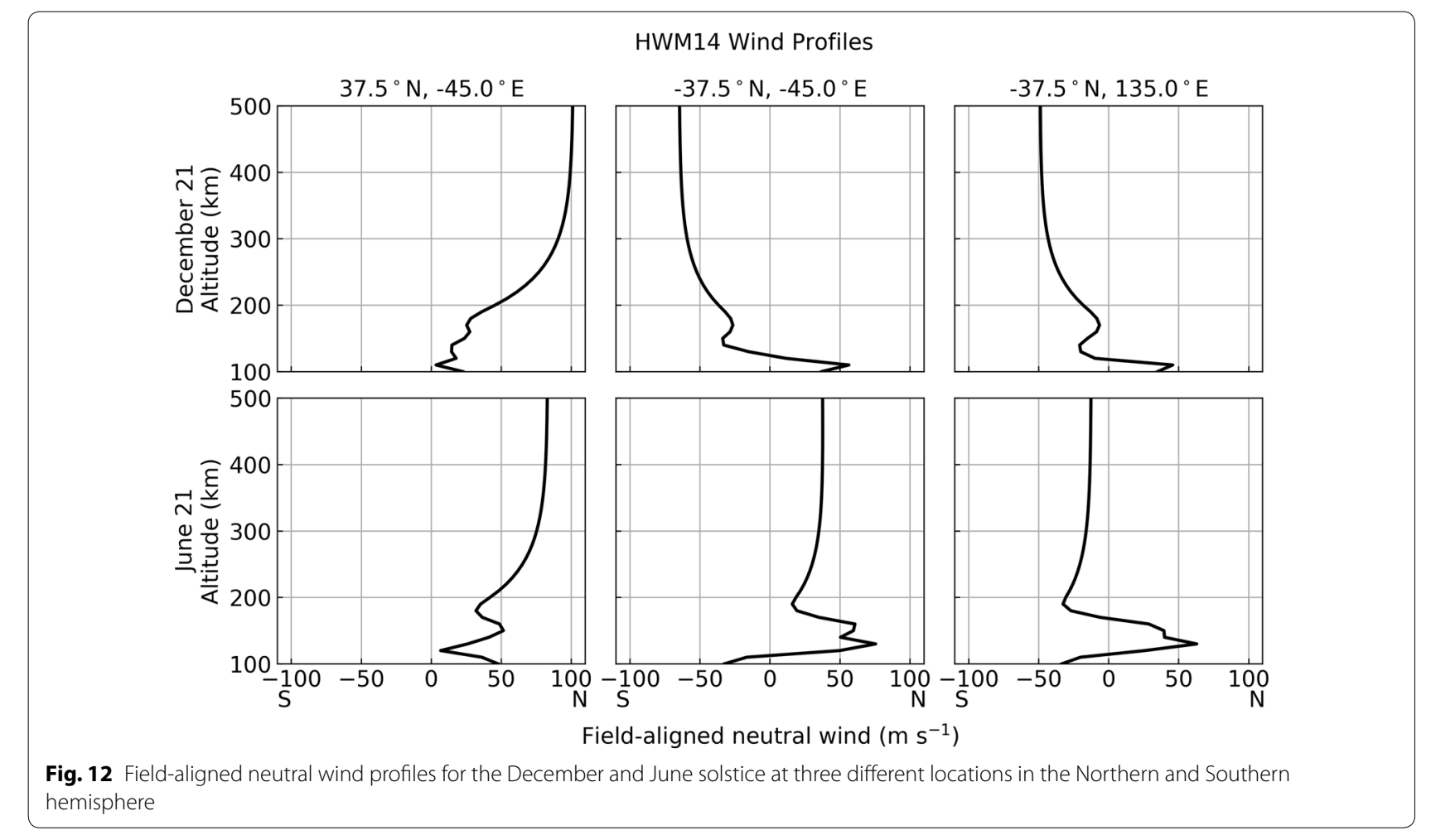

while a negative meridional $\mathbf{E} \times \mathbf{B}$ drift will move the plasma downwards and equatorwards in both hemispheres. In the evening, this means that the terrestrial ionosphere will be maintained for a longer period of time when a positive meridional $\mathbf{E} \times \mathbf{B}$ drift is present, because the plasma will be lifted to higher altitudes where the ion loss rate is lower. Conversely, a negative meridional $\mathbf{E} \times \mathbf{B}$ drift moves any available plasma to lower altitudes where the ion loss rate is higher.

The canonical picture of meridional $\mathbf{E} \times \mathbf{B}$ drift has it directed positively during the day and negatively at night (Kelley 2009). This behavior, when coupled with seasonal variations in photoionisation, explains why the evening Terrestrial TEC slopes are flatter during the summer than during the winter. The seasonal variation can be explained not by a seasonal variation in the direction of the meridional $\mathbf{E} \times \mathbf{B}$ drift, but by the continued presence of photoionisation in the high-latitude ionosphere during the summer. This provides a continual source of plasma to be transported to lower latitudes and altitudes by a negative meridional $\mathbf{E} \times \mathbf{B}$ drift that is not present in the winter. However, this behaviour varies as a function of solar cycle, over the course of the year, and as a function of longitude due to the way that the magnetic declination and neutral wind modify the Pedersen and Hall conductivities (Maute and Richmond 2016; Pacheco et al. 2010). For example, Pacheco et al. (2010) showed that the meridional $\mathbf{E} \times \mathbf{B}$ drift at 19:00 solar local time (a local time that falls between $50^{\circ}$ and $102^{\circ}$ at these latitudes) in general changes from positive to negative with increasing apex altitude. This shows the transition from the low latitude meridional $\mathbf{E} \times \mathbf{B}$ drift, which is strong and directed upward after sunset at higher levels of solar activity, to the mid-latitudes, which has a smoother transition from upward daytime drifts to downward nighttime drifts. However, this variation differs as a function of season and longitude. Specifically, at $0^{\circ}, 310^{\circ}$ and $290^{\circ}$ the meridional $\mathbf{E} \times \mathbf{B}$ drift remains positive for a larger range of apex altitudes during the December solstice than it does during the June solstice. This has stronger implications for the $\mathrm{SH}$ than the $\mathrm{NH}$, since it means that at these longitudes the evening meridional $\mathbf{E} \times \mathbf{B}$ drift will not be moving plasma from high to mid latitudes, leading to the steep summer evening slopes observed in Fig. 11 between $270^{\circ}$ to $360^{\circ}$ (and to a lessor extent $0^{\circ}$ to $90^{\circ}$ ) longitude.

Figure 13 shows the summer:winter slope ratios for the Huber fits to TEC as a function of SZA for $50^{\circ} \leq \mathrm{SZA}$ $\leq 102^{\circ}$. The influence of the seasonal anomaly is seen in most of the location regions. As expected from Figs. 10 and 11, the summer:winter ratio is below one for all the $\mathrm{NH}$ longitudes and the $\mathrm{SH}$ between $90^{\circ}$ and $270^{\circ}$ longitude. At $\mathrm{SH}$ longitudes between $0^{\circ}$ and $90^{\circ}$ the ratio is near one, with a larger value for MY 29 (during solar 


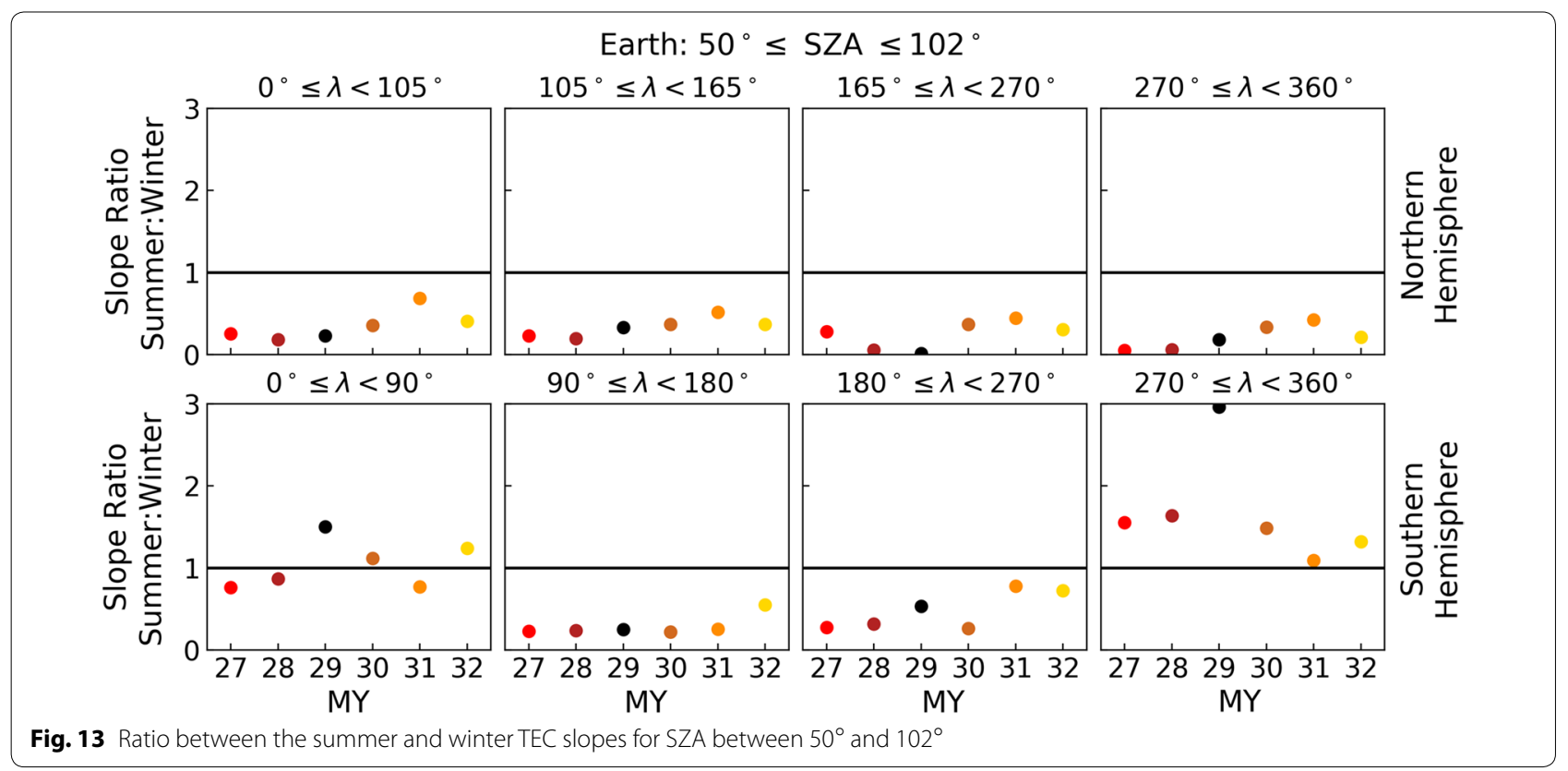

minimum). At $\mathrm{SH}$ longitudes between $270^{\circ}$ and $360^{\circ}$ the ratio is typically near 1.5 , with a larger value (near 3 ) for MY 29. The atypical behavior of these two location regions is consistent with the previous discussion of the annual and longitudinal variations of the meridional $\mathbf{E} \times$ B drift.

Further atypical behaviour seen in the $\mathrm{SH}$ between $270^{\circ}$ and $360^{\circ}$ during MY 29 (solar minimum) suggests that a process in the winter exists to lift the plasma, slowing the recombination rate at a time when then thermosphere was greatly constricted. Figure 3 shows that MY 29 contains the minimum between the $23^{r d}$ and $24^{\text {th }}$ solar cycles, which was very low and has less variation than the solar irradiance during any other MY. Thus, the explanation for the anomalous seasonal ratio at Mars cannot explain what is happening here. However, during this extreme solar minimum, the upper atmosphere was contracted and coupling between the lower atmosphere and ionosphere much more visible than normal. It is possible that lower atmospheric forcing worked together with the contracted thermosphere to cause a slower winter loss rate than were seen elsewhere. This reinforces the interpretation that the terrestrial, mid-latitude ionosphere is more photochemically driven during high levels of solar irradiance and more dominated by transport as the thermosphere contracts.

\section{Mars and Earth comparison}

There is a large difference in ionospheric density between Mars and Earth, which makes direct comparisons of electron density difficult. To get around the differences in TEC magnitude, direct comparisons between Mars and the Earth are made using the dimensionless ratio between the dawn and dusk TEC slopes shown in Figs. 6, 10, and 11. Recall that Table 1 shows that dawn and dusk are defined as containing data with SZA between $\pm 50^{\circ}$ and the SZA of the terminator at ionospheric altitudes.

Figure 14 shows these ratios for all location regions and seasons at Mars and three regions at Earth. These three regions were chosen for closer examination based on their typical or atypical behavior when compared to the rest of the geographic regions. These regions are shown in panels (b) and (d), and plotted on the same vertical scale as the Martian ratios in panels (a) and (c). The Martian ratios are shown on a zoomed scale in Fig. 15, while the remaining Terrestrial ratios are shown in Fig. 16.

As discussed in the Section "Martian TEC", Martian models typically assume strict photochemical equilibrium. This assumption results in a dawn:dusk ratio of unity, which is shown to be a reasonable approximation at Mars when compared to most locations at Earth (for example, compare Fig. 14c and d). There appears to be no clear solar cycle variation in the Martian dawn:dusk ratio and no seasonal dependence. However, the closer examination presented in Fig. 15 reveals that there are times in each of the Martian location regions when the dusk slope is steeper than the dawn slope. The largest differences are seen in the $\mathrm{SH}$ between $150^{\circ}$ and $240^{\circ}$ longitude, where the crustal magnetic fields are strongest, and during the maximum and descending phases of the solar cycle. This reveals that changes in solar irradiance primarily affect photochemical processes, and will not affect the Martian 


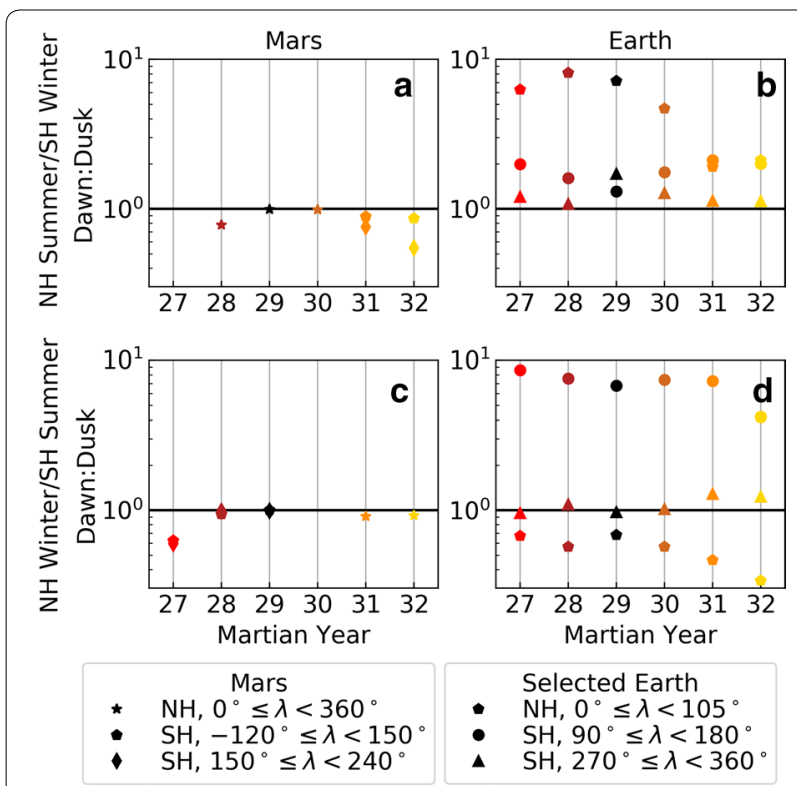

Fig. 14 Ratios between the dawn and dusk TEC slopes for all Martian (left column, $\mathbf{a}$ and $\mathbf{c}$ ) and selected Terrestrial location regions (right column, $\mathbf{b}$ and $\mathbf{d}$ ) as a function of MY. NH summer and $\mathrm{SH}$ winter are shown in the top row (a and $\mathbf{b}$ ), while NH winter and $\mathrm{SH}$ summer are shown in the bottom panels ( $\mathbf{c}$ and $\mathbf{d}$ ). The Martian regions and three of the Terrestrial regions are plotted on the same scale to aid comparison

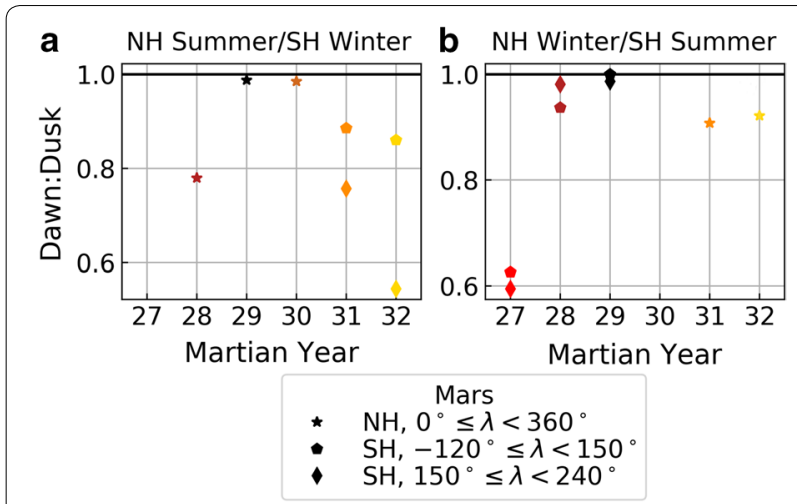

Fig. 15 Ratios between the dawn and dusk TEC slopes for all Martian regions as a function of MY. $\mathrm{NH}$ summer and $\mathrm{SH}$ winter are shown in panel (a), while $\mathrm{NH}$ winter and SH summer are shown in panel (b).

These are the same ratios shown in Fig. 14 (a) and (c), but plotted on a smaller scale to highlight their differences

dawn:dusk ratio. However, when crustal fields are present, processes such as interactions with the solar wind lead to departures from photochemical equilibrium (e.g. Andrews et al. 2015). Our results agree with Matta et al. (2015), who found that strong crustal magnetic field lines alter the structure of the ionosphere mainly by fieldaligned plasma transport, and this is significantly notable

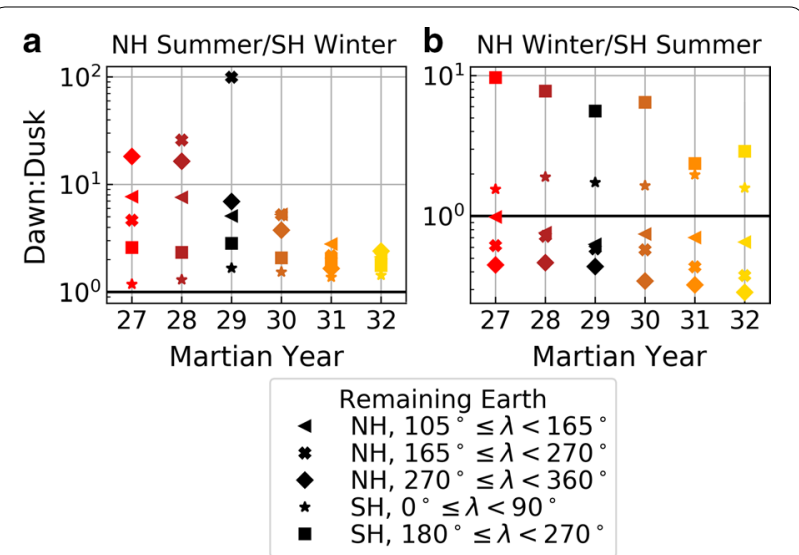

Fig. 16 Ratios between the dawn and dusk TEC slopes for the Terrestrial location regions not shown in Fig. 14 as a function of MY. $\mathrm{NH}$ summer and $\mathrm{SH}$ winter are shown in panel (a), while $\mathrm{NH}$ winter and SH summer are shown in panel (b)

at dusk at high altitude over closed field-lines. A possible explanation for the dawn:dusk ratio solar cycle dependence over the crustal magnetic fields could be that this solar wind interaction with the magnetic field regions could lead to faster recombination at dusk with increased IMF, through processes such as field-aligned plasma transport that also exist in the Terrestrial high latitudes. This variation is characterized by increasing similarly to the Terrestrial ionosphere during $\mathrm{NH}$ winter (compare Fig. 15 and Fig. 14d) with increasing solar activity.

In contrast to the Martian ratios, the Terrestrial dawn:dusk ratio show both seasonal and solar cycle variations in most of the location regions. An exception to this is the $\mathrm{SH}$ region between $270^{\circ}$ and $360^{\circ}$. This longitude region, shown in upward pointing triangles in Fig. 14b and $\mathrm{d}$, has a dawn:dusk ratio that shows little seasonal or solar cycle variation and has values as close to unity as the Martian ratios typically are. This indicates that there are places at Earth where photochemical processes are more important than transport when considering the dawn and dusk plasma production via photoionisation and loss via recombination in the $\mathrm{F}$ region ionosphere (places where the Terrestrial $\mathrm{F}$ region ionosphere behaves more like the Martian ionosphere). However, the strong seasonal and solar cycle variations displayed in the other Terrestrial regions in Fig. 14 suggest that the amount of solar irradiance and the composition of the thermosphere both play a role in the relative importance of photochemical or transport processes.

Figure 14b shows that on Earth in the NH summer, the selected $\mathrm{NH}$ region behaves more photochemically (has a dawn:dusk ratio closer to unity) as solar activity increases. This is consistent with an expanded 
thermosphere allowing plasma recombination to take place at a greater range of heights (minimizing the influence of a downward meridional $\mathbf{E} \times \mathbf{B}$ drift in the summer). The dawn:dusk ratios for the $\mathrm{SH}$ summer regions (Fig. 16a), however, do not show a clear solar cycle variation. This may be attributable to the presence of the Weddell Sea anomaly, a large plasma enhancement that only forms in the $\mathrm{SH}$ summer and extends through much of the mid-latitudes at dusk (Jee et al. 2009).

Figure 14d shows that in the winter, the selected $\mathrm{NH}$ longitude sector behaves less photochemically at higher levels of solar activity. Additionally, the dawn:dusk ratio is now consistently below unity. This implies that either winter transport in the $\mathrm{NH}$ is leading to plasma loss via recombination or that the dawn slope is not solely shaped by plasma production via photoionisation processes. The latter is more likely to be the culprit, as Fig. 10 clearly shows the amount of TEC at the end of the dawn period to be far below the amount of TEC present at the start of the dusk period. Figure $14 \mathrm{~b}$ and $\mathrm{d}$ shows that this is not the case in the $\mathrm{SH}$, where the dawn:dusk ratio is always at or above unity. Instead, Fig. 14b shows that the $\mathrm{SH}$, again, shows no clear solar cycle variation in the dawn:dusk ratio. However, Figs. 14b and 16a show the dawn:dusk ratio in the $\mathrm{NH}$ at high levels of solar activity during the summer is approximately equal to the dawn:dusk ratio seen at all levels of solar activity in the $\mathrm{SH}$ during the winter. These hemispheric and seasonal variations in the Terrestrial dawn:dusk ratio are consistent for the remainder of the $\mathrm{NH}$ and $\mathrm{SH}$ Terrestrial longitude regions shown in Fig. 16.

\section{Conclusions}

This paper used the similarities between the ionospheres on Mars and Earth to examine the relative importance of photochemical and transport processes as functions of location, solar cycle, and season. This was done by comparing the rate of change of TEC as a function of solar zenith angle during the solstice seasons at dawn and dusk. The use of the TEC slopes made it possible to compare production via photoionisation and loss via recombination processes in the main layer of each planetary ionosphere despite the extreme differences in the total quantity of plasma present in the two ionospheres.

To first order, the dawn and dusk slopes that denote the rate of ion production via photoionisation and loss via recombination at Mars are symmetric. This symmetry is interpreted as an indicator of photochemical equilibrium. Although the F region ionosphere at Earth is known to be dominated by transport, there are times and locations where the ratio between the dawn and dusk slopes were found to lie near unity, indicating the local dominance of photochemical processes. Both planets also had times and locations where the dawn and dusk slopes differed significantly. By comparing the two planetary ionospheres at dawn and dusk, these regions were identified and the underlying processes responsible for the plasma transport were explored.

In general, the photochemical processes in both ionospheres behave similarly when no magnetic field is considered. The presence or absence of a magnetic field shape the production via photoionisation and loss via recombination processes in both ionospheres, especially when considering plasma transport. This makes the Terrestrial ionosphere more complex in terms of plasma transport, though similar processes were found and compared (at smaller scales) to similar processes at Mars over crustal fields.

This study has notable implications for comparative aeronomy, as a good understanding of how the ionosphere of magnetised and un-magnetised bodies compares is important for characterising planetary environments. These comparisons are useful for nearby planets such as Mars, but are perhaps even more relevant when attempting to understand the plasma environments of more distant bodies such as the icy moons of the giant planets and rocky exoplanets.

\section{Supplementary information}

Supplementary information accompanies this paper at https://doi. org/10.1186/s40623-020-01258-3.

Additional file 1: Huber regressor linear fit parameters, as well as the medians and quartiles of the difference between the linear fits and observations for each Terrestrial and Martian season, SZA region, MY, and location region as a CSV file.

\section{Abbreviations}

AU: Astronomical unit; AIS: Active lonospheric Sounding; CDDI: Crustal Dynamics Data Information System; CEDAR: Coupling, Energetics and Dynamics of Atmospheric Regions; EIA: Equatorial Ionisation Anomaly; ESA: European Space Agency; EUV: Extreme Ultra Violet; GLONASS: GLObal NAvigation Satellite System; GNSS: Global Navigation System Satellite; GPS: Global Positioning System; HWM: Horizontal wind model; IMF: Interplanetary magnetic field; LISN: Low-Latitude lonospheric Sensor Network; MARSIS: Mars Advanced Radar for Subsurface and lonosphere Sounding; MCD: Mars Climate Database; MIT: Massachusetts Institute of Technology; MY: Martian year; NH: Northern hemisphere; PSA: Planetary Science Archive; RAMSEC CORS: Red Argentina de Monitoreo Satilital Continuo; RENAG: REseau NAtional GPS permanent; SH: Southern Hemisphere; SNR: Signal-to-Noise Ratio; SONEL: Système d'Observation du Niveau des Eaux Littorales; SZA: Solar Zenith Angle; TEC: Total electron content; TIMED/SEE: Thermosphere Ionosphere Mesosphere energetics Dynamics/Solar EUV Experiment; UNAVCO: University Navstar Consortium.

\section{Acknowledgements}

Use of the MCD model through their web interface (http://www-mars.Imd. jussieu.fr/mars/access.html) is acknowledged. GPS TEC data products and access through the Madrigal distributed data system are provided to the community by the Massachusetts Institute of Technology under support from US National Science Foundation grant AGS-1242204. Data for the TEC processing is provided from the following organisations: UNAVCO, Scripps Orbit and Permanent Array Center, Institut Geographique National, France, 
International GNSS Service, The Crustal Dynamics Data Information System (CDDIS), National Geodetic Survey, Instituto Brasileiro de Geografia e Estatística, RAMSAC CORS of Instituto Geográfico Nacional del la República Agentina, Arecibo Observatory, Low-Latitude lonospheric Sensor Network (LISN), Topcon Positioning Systems, Inc., Canadian High Arctic lonospheric Network, Institute of Geology and Geophysics, Chinese Academy of Sciences, China Meterorology Administration, Centro di Ricerche Sismogiche, Système d'Observation du Niveau des Eaux Littorales (SONEL), RENAG : REseau NAtional GPS permanent, and GeoNet - the official source of geological hazard information for New Zealand. Mars Express-MARSIS data can be found at the ESA PSA archive.

\section{Authors' contributions}

AGB co-developed the concept, performed the Earth data analysis, and cowrote the manuscript. BS-C co-developed the concept, performed the Mars data analysis, and co-write the manuscript. OW supported the conceptual development, provided feedback on the data analysis and results, and edited the manuscript. ML provided feedback on the results and edited the manuscript. MC retrieved the Martian TEC and supported the analysis of this data set. All authors read and approved the final manuscript.

\section{Funding}

Funding for BS-C and ML was provided by STFC grant ST/S000429/1. AGB is supported by the Chief of Naval Research through a 6-1 grant provided by the Office of Naval Research. MC gratefully acknowledges support form the Italian Space Agency through contract 2019-21-HH.0.

\section{Availability of data and materials}

The GPS TEC data products are publicly available from the Madrigal data base, which may be accessed through their web interface (http://millstonehill.hayst ack.mit.edu/) or through their application program interface, MadrigalWeb, which is available at: http://cedar.openmadrigal.org. Mars Express-MARSIS data can be found at the ESA PSA archive (https://archives.esac.esa.int/psa/) TIMED/SEE data is publicly available from the University of Colorado Boulder Laboratory for Atmospheric and Space Physics at: http://lasp.colorado.edu/ home/see/data/. HWM14 is provided in the Supplemental Information of Drob et al. (2015). The MCD model is openly accessible through their web interface: http://www-mars.Imd.jussieu.fr/mars/access.html.

\section{Competing interests}

The authors declare that they have no competing interests.

\section{Author details}

1 Space Science Division, U.S. Naval Research Laboratory, Washington D.C., USA. ${ }^{2}$ University of Leicester, Leicester, UK. ${ }^{3}$ European Space Agency, Noordwijk, Netherlands. ${ }^{4}$ Istituto Nazionale di Astrofisica, IAPS Roma, Rome, Italy.

Received: 3 March 2020 Accepted: 25 August 2020

Published online: 24 September 2020

\section{References}

Acuña MH, Connerney JEP, Ness NF, Lin RP, Mitchell D, Carlson CW, McFadden $J$, Anderson KA, Rème H, Mazelle C, Vignes D, Wasilewski P, Cloutier P (1999) Global distribution of crustal magnetization discovered by the Mars Global Surveyor MAG/ER experiment. Science 284:790-793. https ://doi.org/10.1126/science.284.5415.790

Andrews DJ, Edberg NJT, Eriksson Al, Gurnett DA, Morgan D, Němec F, Opgenoorth HJ (2015) Control of the topside martian ionosphere by crustal magnetic fields. J Geophys Res Space Phys 120(4):3042-3058. https:// doi.org/10.1002/2014JA020703

Azpilicueta F, Brunini C, Radicella SM (2011) Semi-annual anomaly and annual asymmetry on TOPEX TEC during a full solar cycle. In: Kenyon S, Pacino MC, Marti U (eds) Geodesy for Planet Earth, vol 136, Springer, Berlin Heidelberg chap 96, pp 769-774. doi: https://doi.org/10.1007/978-3642-20338-1_96

Benna M, Mahaffy PR, Grebowsky JM, Fox JL, Yelle RV, Jakosky BM (2015) First measurements of composition and dynamics of the martian ionosphere by maven's neutral gas and ion mass spectrometer. Geophys Res Lett 42(21):8958-8965. https://doi.org/10.1002/2015GL066146
Bergeot N, Witasse O, Le Maistre S, Blelly PL, Kofman W, Peter K, Dehant V, Chevalier JM (2019) Momo: a new empirical model of the mars ionospheric total electron content based on mars express marsis data. J Space Weather Space Clim 9:A36. https://doi.org/10.1051/swsc/20190 35

Bertaux JL, Leblanc F, Olivier Witasse E, Quemerais Lilensten J, Stern SA, Sandel B, Korablev O (2005) Discovery of an aurora on Mars. Nature 435:790-794

Bougher SW, Engel S, Hinson DP, Murphy JR (2004) MGS radio science electron density profiles: interannual variability and implications for the martian neutral atmosphere. J Geophys Res Planets 109:E3. https://doi. org/10.1029/2003JE002154

Bougher SW, Bell JM, Murphy JR, Lopez-Valverde MA, Withers PG (2006) Polar warming in the Mars thermosphere: seasonal variations owing to changing insolation and dust distributions. Geophys Res Lett. https:// doi.org/10.1029/2005GL024059

Brain D, Barabash S, Boesswetter A, Bougher S, Brecht S, Chanteur G, Hurley D, Dubinin E, Fang X, Fraenz M, Halekas J, Harnett E, Holmstrom M, Kallio E, Lammer H, Ledvina S, Liemohn M, Liu K, Luhmann J, Ma Y, Modolo R, Nagy A, Motschmann U, Nilsson H, Shinagawa H, Simon S, Terada N (2010) A comparison of global models for the solar wind interaction with mars. Icarus 206(1):139-151. https://doi.org/10.1016/j.icaru s.2009.06.030

Brain DA, Halekas JS, Lillis R, Mitchell DL, Lin RP, Crider DH (2005) Variability of the altitude of the martian sheath. Geophys Res Lett. https://doi. org/10.1029/2005GL023126

Cain JC, Ferguson BB, Mozzoni D (2003) An $n=90$ internal potential function of the Martian crustal magnetic field. J Geophys Res 108(E2):5008. https ://doi.org/10.1029/2000JE001487

Cao YT, Cui J, Wu XS, Guo JP, Wei Y (2019) Structural variability of the nightside martian ionosphere near the terminator: implications on plasma sources. J Geophys Res Planets 124(6):1495-1511. https://doi. org/10.1029/2019JE005970

Cartacci M, Amata E, Cicchetti A, Noschese R, Giuppi S, Langlais B, Frigeri A, Orosei R, Picardi G (2013) Mars ionosphere total electron content analysis from MARSIS subsurface data. Icarus 223:423-437. https://doi. org/10.1016/j.icarus.2012.12.011

Cartacci M, Sánchez-Cano B, Orosei R, Noschese R, Cicchetti A, Witasse O, Cantini F, Pio Rossi A (2018) Improved estimation of Mars ionosphere total electron content. Icarus 299:396-410. https://doi.org/10.1016/j. icarus.2017.07.033

Chapman S (1931) Absorption and dissociative or ionising effects of monochromatic radiation in an atmosphere on a rotating earth. Proc Phys Soc London 43:1047-1055

Chen RH, Cravens TE, Nagy AF (1978) The martian ionosphere in light of the viking observations. J Geophys Res Space Phys 83(A8):3871-3876. https ://doi.org/10.1029/JA083iA08p03871

Chicarro A, Martin P, Traunter R (2004) Mars express: a European mission to the red planet. European Space Agency Publication Division, Noordwijk, Netherlands

Cravens TE, Hamil O, Houston S, Bougher S, Ma Y, Brain D, Ledvina S (2017) Estimates of ionospheric transport and ion loss at mars. J Geophys Res Space Phys 122(10):10,626-10,637. https://doi.org/10.1002/2017JA0245 82

Cui J, Galand M, Yelle RV, Wei Y, Zhang SJ (2015) Day-to-night transport in the martian ionosphere: implications from total electron content measurements. J Geophys Res Space Phys 120(3):2333-2346. https://doi. org/10.1002/2014JA020788

Drob DP, Emmert JT, Meriwether JW, Makela JJ, Doornbos E, Conde M, Hernandez G, Noto J, Zawdie KA, McDonald SE, Huba JD, Klenzing JH (2015) An update to the horizontal wind model (HWM): the quiet time thermosphere. Earth Space Sci 2:301-319. https://doi.org/10.1002/2014E A000089

Dungey JW (1961) Interplanetary magnetic field and the auroral zones. Phys Rev Lett 6(2):47-48

Duru F, Gurnett DA, Averkamp TF, Kirchner DL, Huff RL, Persoon AM, Plaut JJ, Picardi G (2006) Magnetically controlled structures in the ionosphere of mars. J Geophys Res Space Phys. https://doi.org/10.1029/2006JA011975

Eckermann SD, Ma J, Hoppel KW, Kuhl DD, Allen DR, Doyle JA, Viner KC, Ruston BC, Baker NL, Swadley SD, Whitcomb TR, Reynolds CA, Xu L, Kaifler N, Kaifler B, Reid IM, Murphy DJ, Love PT (2018) High-altitude (0-100 km) 
global atmospheric reanalysis system: description and application to the 2014 austral winter of the deep propagating gravity wave experiment (DEEPWAVE). Monthly Weather Rev 146(8):2639-2666. https://doi. org/10.1175/mwr-d-17-0386.1

Edberg NJT, Lester M, Cowley SWH, Eriksson Al (2008) Statistical analysis of the location of the Martian magnetic pileup boundary and bow shock and the influence of crustal magnetic fields. J Geophys Res Space Phys. https://doi.org/10.1029/2008JA013096

Emmert JT, Lean JL, Picone JM (2010) Record-low thermospheric density during the 2008 solar minimum. Geophys Res Lett 37(L12):102. https://doi. org/10.1029/2010GL043671

Evans JV, Holt JM (1978) Nighttime proton fluxes at Millstone Hill. Planetary Space Sci 26:727-744

Forget F, Hourdin F, Fournier R, Hourdin C, Talagrand O (1999) Improved general circulation models of the Martian atmosphere from the surface to above $80 \mathrm{~km}$. J Geophys Res 104(E10):24,155-24,175. https://doi. org/10.1029/1999JE001025

Fox JL (1997) Upper limits to the outflow of ions at mars: implications for atmospheric evolution. Geophys Res Lett 24(22):2901-2904. https://doi. org/10.1029/97GL52842

Fox JL (2009) Morphology of the dayside ionosphere of mars: implications for ion outflows. J Geophys Res Planets. https://doi.org/10.1029/2009J E003432

Frissell NA, Baker JBH, Ruohoniemi JM, Greenwald RA, Gerrard AJ, Miller ES, West ML (2016) Sources and characteristics of medium-scale traveling ionospheric disturbances observed by high-frequency radars in the North American sector. J Geophys Res Space Phys 121(4):3722-3739. https://doi.org/10.1002/2015JA022168

Fuller-Rowell TJ (1998) The "thermospheric spoon": a mechanism for the semiannual density variation. J Geophys Res 103(A3):3951-3956

Fuller-Rowell TJ, Rees D, Quegan S, Moffett RJ, Bailey GJ (1988) Simulations of the seasonal and universal time variations of the high-latitude thermosphere and ionosphere using a coupled, three-dimensional, model. Pure Appl Geophys 127(2):189-217

Girazian Z, Mahaffy PR, Lillis RJ, Benna M, Elrod M, Jakosky BM (2017) Nightside ionosphere of mars: composition, vertical structure, and variability. J Geophys Res Space Phys 122(4):4712-4725. https://doi. org/10.1002/2016JA023508

Goncharenko LP, Coster AJ, Chau JL, Valladares CE (2010) Nightside ionosphere of mars: composition, vertical structure, and variability. J Geophys Res 115:A00G07. https://doi.org/10.1029/2010JA015400

González-Galindo F, Chaufray JY, López-Valverde MA, Gilli G, Forget F, Leblanc F, Modolo R, Hess S, Yagi M, (2013) Three-dimensional Martian ionosphere model: I. The photochemical ionosphere below $180 \mathrm{~km}$. J Geophys Res Planets 118:2105-2123. https://doi.org/10.1002/jgre.20150

Gupta N, Rao NV, Kadhane UR (2019) Dawn-dusk asymmetries in the Martian upper atmosphere. J Geophys Res Planets. https://doi. org/10.1029/2019je006151

Gurnett DA, Kirchner DL, Huff RL, Morgan DD, Persoon AM, Averkamp TF, Duru F, Nielsen E, Safaeinili A, Plaut JJ, Picardi G (2005) Radar soundings of the ionosphere of Mars. Science 310(5756):1929-1933. https://doi. org/10.1126/science.1121868

Hagan ME, Forbes JM (2002) Migrating and nonmigrating diurnal tides in the middle and upper atmosphere excited by tropospheric latent heat release. J Geophys Res 107(D24):4754. https://doi.org/10.1029/2001J D001236

Halekas JS (2017) Seasonal variability of the hydrogen exosphere of Mars. J Geophys Res Planets 122(5):901-911. https://doi.org/10.1002/2017J E005306

Halekas JS, Brain DA, Luhmann JG, DiBraccio GA, Ruhunusiri S, Harada Y, Fowler CM, Mitchell DL, Connerney JEP, Espley JR, Mazelle C, Jakosky BM (2017) Flows, fields, and forces in the Mars-Solar wind interaction. J Geophys Res Space Phys 122(11):11,320-11,341. https://doi.org/10.1002/2017J A024772

Hall BES, Lester M, Nichols JD, Sánchez-Cano B, Andrews DJ, Opgenoorth HJ, Fränz M (2016a) A survey of superthermal electron flux depressions, or "electron holes," within the illuminated Martian induced magnetosphere. J Geophys Res Space Phys 121(5):4835-4857. https://doi. org/10.1002/2015JA021866

Hall BES, Lester M, Sánchez-Cano B, Nichols JD, Andrews DJ, Edberg NJT, Opgenoorth HJ, Fränz M, Holmström M, Ramstad R, Witasse O, Cartacci
M, Cicchetti A, Noschese R, Orosei R (2016b) Annual variations in the Martian bow shock location as observed by the Mars Express mission. J Geophys Res Space Phys 121(11):11,474-11,494. https://doi. org/10.1002/2016JA023316

Hanson WB, Moffett RJ (1966) lonization transport effects in the equatorial F region. J Geophys Res 71:5559-5571. https://doi.org/10.1029/JZ071 i023p05559

Hanson WB, Sanatani S, Zuccaro DR (1977) The martian ionosphere as observed by the viking retarding potential analyzers. J Geophys Res (1896-1977) 82(28):4351-4363. https://doi.org/10.1029/JS082i028p 04351

Heelis RA (2004) Electrodynamics in the low and middle latitude ionosphere: tutorial. J Atmospheric Solar Terrestrial Phys 66(10):825-838

Huber PJ (1963) Robust estimation of a location parameter. Ann Math Stat 35(1):73-101

Immel TJ, Sagawa E, England SL, Henderson SB, Hagan ME, Mende SB, Frey HU, Swenson CM, Paxton L (2006) Control of equatorial ionospheric morphology by atmospheric tides. Geophys Res Lett 33(L15):108. https ://doi.org/10.1029/2006GL026161

Jee G, Burns AG, Kim YH, Wang W (2009) Seasonal and solar activity variations of the Weddell Sea anomaly observed in the TOPEX total electron content measurements. J Geophys Res Space Phys. https://doi. org/10.1029/2008JA013801

Jones M, Emmert JT, Drob DP, Picone JM, Meier RR (2018) Origins of the thermosphere-ionosphere semiannual oscillation: reformulating the "thermospheric spoon" mechanism. J Geophys Res Space Phys 123(1):931-954. https://doi.org/10.1002/2017ja024861

Kar J, Mahajan KK, Kohli R (1996) On the outflow of o2 + ions at mars. J Geophys Res Planets 101(E5):12,747-12,752. https://doi.org/10.1029/95JE0 3526

Kartalev M, Rycroft M, Papitashvili V (2004) A quantitative model of the effect of global thunderstorms on the global distribution of ionospheric electrostatic potential. J Atmospheric Solar Terrestrial Phys 66(13):12331240. https://doi.org/10.1016/j.jastp.2004.05.012

Kelley MC (2009) The Earth's ionosphere: plasma physics and electrodynamics, International Geophysics Series, vol 96, 2nd edn. San Diego, Elsevier

Kersley L, Hajeb-Hosseinieh H, Edwards KJ (1978) Plasma fluxes between ionosphere and protonosphere. Nature 271:427-429

Lillis RJ, Mitchell DL, Steckiewicz M, Brain D, Xu S, Weber T, Halekas J, Connerney J, Espley J, Benna M, Elrod M, Thiemann E, Eparvier F (2018) Ionizing electrons on the martian nightside: structure and variability. J Geophys Res Space Phys 123(5):4349-4363. https://doi.org/10.1029/2017JA0251 51

Lühr H, Häusler K, Stolle C (2007) Longitudinal variation of F region electron density and thermospheric zonal wind caused by atmospheric tides. Geophys Res Lett 34(L16):102. https://doi.org/10.1029/2007GL030639

Macmillan S, Finlay C (2010) The International Geomagnetic Reference Field. Geomagnetic Observations and Models. Springer Netherlands, Dordrecht, pp 265-276, https://doi.org/10.1007/978-90-481-9858-0_10

Matta M, Mendillo M, Withers P, Morgan D (2015) Interpreting mars ionospheric anomalies over crustal magnetic field regions using a 2-d ionospheric model. J Geophys Res Space Phys 120(1):766-777. https:// doi.org/10.1002/2014JA020721

Maute A, Richmond AD (2016) F-region dynamo simulations at low and mid-latitude. Space Science Reviews. pp 1-23, https://doi.org/10.1007/ s11214-016-0262-3

Mazelle C, Winterhalter D, Sauer K, Trotignon J, Acuña M, Baumgärtel K, Bertucci C, Brain D, Brecht S, Delva M, Dubinin E, Øieroset M, Slavin 」 (2004) Bow shock and upstream phenomena at Mars. Space Sci Rev 111 (1):115-181. https://doi.org/10.1023/B:SPAC.0000032717.98679.d0

Mendillo M, Smith S, Wroten J, Rishbeth H (2003) Simultaneous ionospheric variability on Earth and Mars. J Geophys Res 108(A12):1432. https://doi. org/10.1029/2003JA009961

Mendillo M, Lollo A, Withers P, Matta M, Pätzold M, Tellmann S (2011) Modeling mars' ionosphere with constraints from same-day observations by mars global surveyor and mars express. J Geophys Res Space Phys. https:// doi.org/10.1029/2011JA016865

Mendillo M, Narvaez C, Lawler G, Kofman W, Mouginot J, Morgan D, Gurnett D (2015) The equivalent slab thickness of mars'ionosphere: implications for thermospheric temperature. Geophys Res Lett 42(9):3560-3568. https://doi.org/10.1002/2015GL063096 
Mendillo M, Trovato J, Narvaez C, Mayyasi M, Moore L, Vogt MF, Fallows K, Withers P, Martinis C (2016) Comparative aeronomy: molecular ionospheres at Earth and Mars. J Geophys Res Space Phys 121(10):10,269-10,288. https://doi.org/10.1002/2016JA023097

Meriwether JW (1983) Observations of thermospheric dynamics at high latitudes from ground and space. Radio Sci 18(6):1035-1052. https://doi. org/10.1029/RS018i006p01035

Millour E, Forget F, Spiga A, Vals M, Zakharov V, Montabone L, Lefèvre F, Montmessin F, Chaufray JY, López-Valverde MA, González-Galindo F, Lewis SR, Read PL, Desjean MC, Cipriani F, the MCD development team (2018) The Mars Climate Database (version 5.3). In: From Mars Express to ExoMars

Mouginot J, Kofman W, Safaeinili A, Herique A (2008) Correction of the ionospheric distortion on the MARSIS surface sounding echoes. Planet Space Sci 56:917-926. https://doi.org/10.1016/j.pss.2008.01.010

Nĕmec F, Morgan DD, Gurnett DA, Duru F (2010) Nightside ionosphere of mars: radar soundings by the mars express spacecraft. J Geophys Res Planets. https://doi.org/10.1029/2010JE003663

Occhipinti G, Kherani EA, Lognonné P (2008) Geomagnetic dependence of ionospheric disturbances induced by tsunamigenic internal gravity waves. Geophys J Int 173:753-765. https://doi.org/10.1111/j.1365246X.2008.03760.x

Ogawa T, Nishitani N, Tsugawa T, Shiokawa K (2012) Giant ionospheric disturbances observed with the SuperDARN hokkaido HF radar and GPS network after the 2011 tohoku earthquake. Earth Planets Space 64(12):1295-1307. https://doi.org/10.5047/eps.2012.08.001

Orosei R, Jordan R, Morgan D, Cartacci M, Cicchetti A, Duru F, Gurnett D, Heggy E, Kirchner D, Noschese R, Kofman W, Masdea A, Plaut J, Seu R, Watters T, Picardi G (2015) Mars advanced radar for subsurface and ionospheric sounding (MARSIS) after nine years of operation: a summary. Planet Space Sci 112:98-114. https://doi.org/10.1016/j.pss.2014.07.010

Orosei R, Lauro SE, Pettinelli E, Cicchetti A, Coradini M, Cosciotti B, Di Paolo F, Flamini E, Mattei E, Pajola M, Soldovieri F, Cartacci M, Cassenti F, Frigeri A, Giuppi S, Martufi R, Masdea A, Mitri G, Nenna C, Noschese R, Restano M, Seu R (2018) Radar evidence of subglacial liquid water on Mars. Science 361 (6401):490-493. https://doi.org/10.1126/science.aar7268

Pacheco EE, Heelis RA, Su SY (2010) Quiet time meridional (vertical) ion drifts at low and middle latitudes observed by ROCSAT-1. J Geophys Res Space Phys. https://doi.org/10.1029/2009JA015108

Pedregosa F, Varoquaux G, Gramfort A, Michel V, Thirion B, Grisel O, Blondel M, Prettenhofer P, Weiss R, Dubourg V, Vanderplas J, Passos A, Cournapeau D, Brucher M, Perrot M, Duchesnay E (2011) Scikit-learn: machine learning in Python. J Mach Learn Res 12:2825-2830

Picardi G, Biccari D, Seu R, Plaut J, Johnson WTK, Jordan RL, Safaeinili A, Gurnett DA, Huff R, Orosei R, Bombaci O, Calabrese D, Zampolini E (2004) MARSIS: Mars Advanced Radar for Subsurface and lonosphere Sounding. Mars express: a European mission to the red planet. European Space Agency Publication Division, Noordwijk, Netherlands., pp 51-70

Ramírez-Nicolás M, Sánchez-Cano B, Witasse O, Blelly PL, Vázquez L, Lester $M$ (2016) The effect of the induced magnetic field on the electron density vertical profile of the mars'ionosphere: a Mars Express MARSIS radar data analysis and interpretation, a case study. Planetary Space Sci 126:49-62. https://doi.org/10.1016/.jpss.2016.03.017

Richards PG, Fennelly JA, Torr DG (1994) EUVAC: a solar EUV flux model for aeronomic calculations. J Geophys Res 99(A5):8981-8992

Rideout W, Coster AJ (2006) Automated GPS processing for global total electron content data. GPS Solutions 10(3):219-228. https://doi. org/10.1007/s10291-006-0029-5

Rishbeth H, Mendillo M (2004) lonospheric layers of Mars and Earth. Planetary Space Sci 52(9):849-852. https://doi.org/10.1016/j.pss.2004.02.007

Safaeinili A, Kofman W, Mouginot J, Gim Y, Herique A, Ivanov AB, Plaut J, Picardi G (2007) Estimation of the total electron content of the Martian ionosphere using radar sounder surface echoes. Geophys Res Lett. https://doi.org/10.1029/2007GL032154

Sánchez-Cano B, Radicella S, Herraiz M, Witasse O, Rodríguez-Caderot G (2013) NeMars: an empirical model of the martian dayside ionosphere based on Mars Express MARSIS data. Icarus 225(1):236-247. https://doi. org/10.1016/j.icarus.2013.03.021

Sánchez-Cano B, Lester M, Witasse O, Milan SE, Hall BES, Blelly PL, Radicella SM, Morgan DD (2015a) Evidence of scale height variations in the
Martian ionosphere over the solar cycle. J Geophys Res Space Phys 120(12):10,913-10,925. https://doi.org/10.1002/2015JA021949

Sánchez-Cano B, Morgan DD, Witasse O, Radicella SM, Herraiz M, Orosei R, Cartacci M, Cicchetti A, Noschese R, Kofman W, Grima C, Mouginot J, Gurnett DA, Lester M, Blelly PL, Opgenoorth H, Quinsac G (2015b) Total electron content in the martian atmosphere: a critical assessment of the Mars Express MARSIS data sets. J Geophys Res Space Phys 120(3):2166-2182. https://doi.org/10.1002/2014JA020630

Sánchez-Cano B, Lester M, Witasse O, Milan SE, Hall BES, Cartacci M, Peter K, Morgan DD, Blelly PL, Radicella S, Cicchetti A, Noschese R, Orosei R, Pätzold M (2016) Solar cycle variations in the ionosphere of Mars as seen by multiple Mars Express data sets. J Geophys Res Space Phys 121(3):2547-2568. https://doi.org/10.1002/2015JA022281

Sánchez-Cano B, Lester M, Witasse O, Blelly PL, Indurain M, Cartacci M, González-Galindo F, Vicente-Retortillo Á, Cicchetti A, Noschese R (2018) Spatial, seasonal, and solar cycle variations of the Martian Total Electron Content (TEC): Is the TEC a good tracer for atmospheric cycles? J Geophys Res Planets 123(7):1746-1759. https://doi.org/10.1029/2018J E005626

Sánchez-Cano B, Blelly PL, Lester M, Witasse O, Cartacci M, Orosei R, Opgenoorth H, Lillis R, Leblanc F, Milan SE, Conroy P, Floury N, Plane JMC, Cicchetti A, Noschese R, Kopf AJ (2019) Origin of the extended mars radar blackout of september 2017. J Geophys Res Space Phys 124(6):45564568. https://doi.org/10.1029/2018JA026403

Schunk RW, Nagy AF (2009) lonospheres: Physics, Plasma Physics, and Chemistry, 2nd edn. Atmospheric and Space Science Series, Cambridge University Press, New York, NY (USA), https://doi.org/10.1017/CBO97 80511635342

Shinagawa H, Cravens TE (1989) A one-dimensional multispecies magnetohydrodynamic model of the dayside ionosphere of Mars. J Geophys Res 94(A6):6506-6516

Syrovatskii SI (1978) Freezing-in condition for a magnetic field and current sheets in plasma. Astrophysics Space Sci 56:3-12

The MathWorks, Inc (2019) Regress. https://uk.mathworks.com/help/stats/ robustfit.html

Wang JS, Nielsen E (2003) Behavior of the Martian dayside electron density peak during global dust storms. Planetary Space Sci 51(4):329-338. https://doi.org/10.1016/50032-0633(03)00015-1

Wang JS, Nielsen E (2004) Evidence for topographic effects on the Martian ionosphere. Planetary Space Sci 52(9):881-886. https://doi.org/10.1016/j. pss.2004.01.008

Welling D, André M, Dandouras I, Delcour D, Fazakerly A, Fontaine D, Foster J, Ilie R, Kistler L, Lee J, Leimohn M, Slavin J, Wang CP, Wiltberger M, Yau A (2015) The Earth: plasma sources, losses, and transport processes. Space Sci Rev 192:145-208. https://doi.org/10.1007/s11214-015-0187-2

Witasse O, Cravens T, Mendillo M, Moses J, Kliore A, Nagy AF, Breus T (2008) Solar system ionospheres. Space Sci Rev 139(1):235-265. https://doi. org/10.1007/s11214-008-9395-3

Withers P (2009) A review of observed variability in the dayside ionosphere of Mars. Adv Space Res 44(3):277-307. https://doi.org/10.1016/j. asr.2009.04.027

Withers P, Fillingim MO, Lillis RJ, Häusler B, Hinson DP, Tyler GL, Pätzold M, Peter K, Tellmann S, Witasse O (2012) Observations of the nightside ionosphere of mars by the mars express radio science experiment (mars). J Geophys Res Space Phys. https://doi.org/10.1029/2012JA018185

Woods TN, Eparvier FG, Bailey SM, Chamberlin PC, Lean J, Rottman GJ, Solomon SC, Tobiska WK, Woodraska DL (2005) Solar EUV Experiment (SEE): mission overview and first results. J Geophys Res 110(A01):312. https:// doi.org/10.1029/2004JA010765

Wu XS, Cui J, Xu SS, Lillis RJ, Yelle RV, Edberg NJT, Vigren E, Rong ZJ, Fan K, Guo JP, Cao YT, Jiang FY, Wei Y, Mitchell DL (2019) The morphology of the topside martian ionosphere: implications on bulk ion flow. J Geophys Res Planets 124(3):734-751. https://doi.org/10.1029/2018JE005895

Yiğit E, Medvedev AS, Aylward AD, Hartogh P, Harris MJ (2009) Modeling the effects of gravity wave momentum deposition on the general circulation above the turbopause. J Geophys Res Atmospheres. https://doi. org/10.1029/2008JD011132

Yiğit E, England SL, Liu G, Medvedev AS, Mahaffy PR, Kuroda T, Jakosky BM (2015) High-altitude gravity waves in the Martian thermosphere observed by MAVEN/NGIMS and modeled by a gravity wave scheme. 
Geophys Res Lett 42(21):8993-9000. https://doi.org/10.1002/2015G L065307

Yonezawa T (1959) On the seasonal and non-seasonal annual variations and the semi-annual variation in the noon and midnight electron densities of the F2 layer in middle latitudes. II. J Radio Res Laboratories 6(28):651-668

Yonezawa T, Arima Y (1959) On the seasonal and non-seasonal annual variations and the semi-annual variation in the noon and midnight electron densities of the F2 layer in middle latitudes. J Radio Res Laboratories 6(25):293-309
Zou H, Lillis RJ, Wang JS, Nielsen E (2011) Determination of seasonal variations in the Martian neutral atmosphere from observations of ionospheric peak height. J Geophys Res 116(E09):004. https://doi.org/10.1029/2011 E003833

\section{Publisher's Note}

Springer Nature remains neutral with regard to jurisdictional claims in published maps and institutional affiliations.

\section{Submit your manuscript to a SpringerOpen ${ }^{\circ}$ journal and benefit from:}

- Convenient online submission

- Rigorous peer review

- Open access: articles freely available online

- High visibility within the field

- Retaining the copyright to your article

Submit your next manuscript at $\boldsymbol{\nabla}$ springeropen.com 